\title{
Climate impacts of anthropogenic land use changes on the Tibetan Plateau
}

\author{
Xuefeng Cui ${ }^{\text {a,c,* }}$, Hans-F. Graf ${ }^{\text {a,b,1 }}$, Baerbel Langmann ${ }^{\text {a,2 }}$, \\ Wen Chen ${ }^{\mathrm{c}, 3}$, Ronghui Huang ${ }^{\mathrm{c}, 3}$ \\ a Max Planck Institute for Meteorology, Bundesstrasse 53, D-20146, Hamburg, Germany \\ ${ }^{\mathrm{b}}$ University of Cambridge, Cambridge CB2 3EN, UK \\ c Institute of Atmospheric Physics, Chinese Academy of Sciences, 100028 Beijing, China
}

Received 3 March 2005; received in revised form 27 June 2005; accepted 5 July 2005

Available online 27 June 2006

\begin{abstract}
A general atmospheric circulation model (ECHAM5) has been applied to investigate the impact of land use changes on the Tibetan Plateau (TP) on local and global climate. The "control" simulation with current land cover reasonably represents the largescale circulation and state of the atmosphere over the Tibetan Plateau and the surrounding region. Modifying the land cover to a hypothetical non-anthropogenically-influenced vegetation cover shows significant modifications to the local and remote climate. Compared to this scenario, the TP is warmer and drier under present conditions. The Indian summer monsoon is intensified and the East China summer monsoon is weakened due to human-induced land cover change on the TP. The mean global temperature has almost no variation, whereas precipitation slightly increases. Our study indicates that human-induced land use changes on the Tibetan Plateau have had a significant impact on local to regional, and to a lesser extent global, climate.
\end{abstract}

(C) 2006 Elsevier B.V. All rights reserved.

Keywords: Tibetan Plateau; land use change; monsoon; GCM

\section{Introduction}

Land use changes (LUC) by human activities, such as deforestation, urbanization, and agriculture practice, have long been known to influence climate (e.g. Charney, 1975). Land surface conditions affect the dynamics and

\footnotetext{
* Corresponding author. Now at: Department of Geography, Roxby Building, University of Liverpool, Liverpool L69 7ZT, UK. Tel.: +44 151 7942855; fax: +44 7942866.

E-mail addresses: xuefng@dkrz.de (X. Cui),hfg21@cam.ac.uk (H.-F. Graf), langmann@dkrz.de (B. Langmann), chenw@lasg.iap.ac.cn (W. Chen), hrh@lasg.iap.ac.cn (R. Huang).

${ }^{1}$ Tel.: +44 1223 330242; fax: +44 1223333392.

${ }^{2}$ Tel.: +49 40 41173239; fax: +49 4041173298 .

${ }^{3}$ Tel.: +86 10 62551597; fax: +86 1062560390 .
}

thermodynamics of the atmosphere by influencing the water cycle and energy budget. LUC may affect local, regional, and possibly global weather and climate (e.g. Werth and Avissar, 2002). Previous studies of the impact of LUC on climate have mostly investigated the effects of tropical deforestations (e.g. Shukla et al., 1990; Nobre et al., 1991; Henderson-Sellers et al., 1993) and the impacts of Saharan desertification (e.g. Xue, 1997; Clark et al., 2001; Snyder and Foley, 2004). Recently, some studies have focused on the interaction of LUC and climate in East Asia (e.g. Yatagai and Yasunari, 1995; Xue, 1996; Fu, 2003). To our knowledge, no such study has been performed investigating LUC/climate interactions over the Tibetan Plateau (TP) region so far. A limitation of most performed studies has been that they 
investigated distinct local and regional responses to LUC. Regional responses, however, are highly variable from one location to another (e.g. Govindasamy et al., 2001), and even within the same region, responses vary depending on the prevailing climatic conditions (e.g. Pan et al., 1999). A solution to this high variability is to perform detailed regional studies to assess specific responses of LUC in different parts of the world (Xue et al., 2004), permitting greater insight into the impacts of LUC on global climate.

Mountainous and high-elevated regions, such as the $\mathrm{TP}$, are very vulnerable to climate change (e.g. Beniston, 2003). As referred to in this paper, the TP is the geographic region with elevation higher than $3000 \mathrm{~m}$, including the Tibet Autonomous Region, Qinghai province, parts of Sichuan and Gansu provinces, and part of the Xinjiang Uygur Autonomous region (shaded region in Fig. 1). Because of its height (average elevation of $4200 \mathrm{~m}$ ) and size (about $1 \times 10^{6}$ square kilometers), the TP plays an important role in forming and inducing variations of regional weather and climate in east and south Asia, as well as the Northern Hemisphere atmospheric circulation in general (e.g. Ye and Gao, 1979). Analyses of temperature series of 97 stations showed that most of the TP has experienced statistically significant warming since the mid-1950s, especially in winter. The linear rates of the temperature increase over the TP during the period of $1955-1996$ was about $0.16{ }^{\circ} \mathrm{C} /$ decade for the annual mean and $0.32{ }^{\circ} \mathrm{C} /$ decade for the winter mean, exceeding those for the Northern Hemi- sphere and the same latitudinal zone in the same period (Liu and Chen, 2000). Frauenfeld et al. (2005) confirmed such warming trends on the TP during the period of 1957-2000 based on the analysis of 161 station records. As a result of the rising air temperature, the lower altitude limit of permafrost has risen by $40-80 \mathrm{~m}$ on the TP (Li and Cheng, 1999) and the permafrost area on the TP has decreased by $10,000 \mathrm{~km}^{2}$ in the recent years (Wang et al., 2000). The southeast of the TP was also growing wetter during the last 40 years shown for the station records (Niu et al., 2004). Tree ring records show a positive trend of late summer rainfall in the southeast TP for the period of 1961-1990 (Braeuning and Mantwill, 2004) and an increase of spring precipitation since the 1970s over the western Himalayan region (Singh and Yadav, 2005). Despite these wetter conditions, the level of Qinghai lake, the largest lake on the TP, has fallen dramatically and shrunk in area since the beginning of 20th century, mainly due to the decrease of precipitation in the catchments area (Qin and Huang, 1998). As the TP is characterized by very complex terrain and weather stations are biased to the eastern, lower-elevation, populated areas, observational data is not ideal for assessing long-term trends on the TP (Frauenfeld et al., 2005). The results obtained from the studies described above can only represent the available data sources they used. They indicate an obvious warming climate on the TP in recent decades. Frauenfeld et al. (2005), however, found that there are no significant trends on the TP in its 2-m temperature from European Centre for Medium-Range

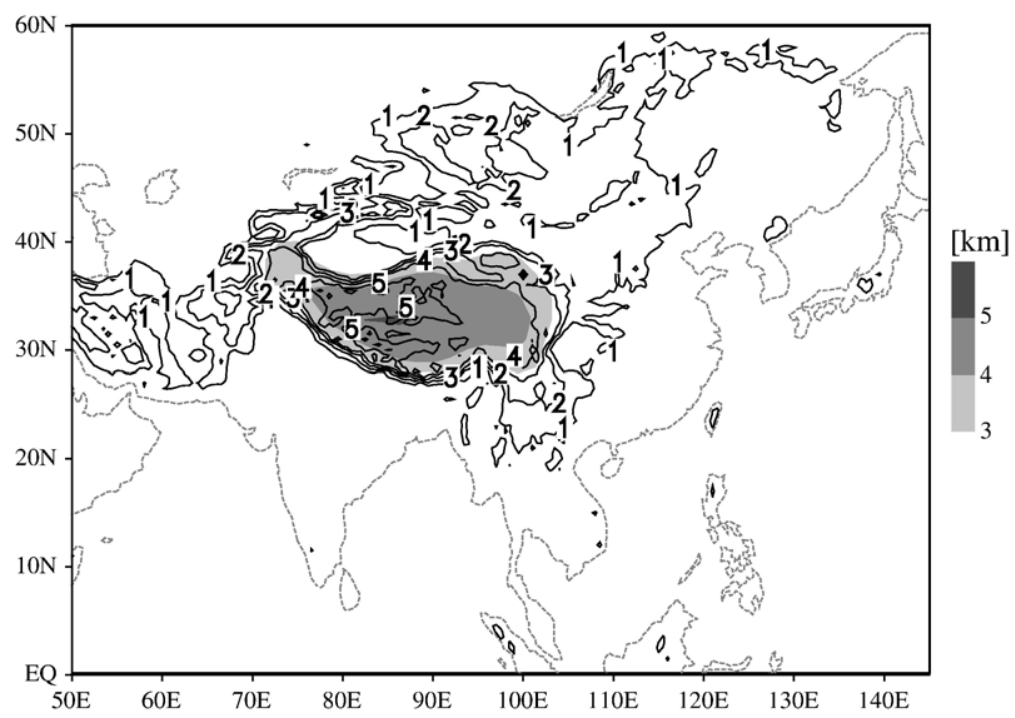

Fig. 1. The main topography over the Tibetan Plateau and its vicinity. The Tibetan Plateau is shown as the shaded region where elevation is higher than $3000 \mathrm{~m}$ a.s.1. at T63 resolution. Black contour lines show topography at $0.5^{\circ}$ resolution with an interval of $1000 \mathrm{~m}$. Data is obtained from the Advanced Very High Resolution Radiometer (AVHRR) satellite data. 
Weather Forecasts (ECMWF) Reanalysis (ERA40; Simmons and Gibson, 2000). Kalnay and Cai (2003) suggested a potential explanation for the difference between reanalysis and station trend is the extensive local and regional land use changes during recent decades.

Grassland occupies about $50 \%$ of the TP and is mostly used for livestock grazing. Over the last 30 years, livestock numbers across the TP have increased more than $200 \%$ due to inappropriate land management practices (Du et al., 2004). Land use represents the most substantial human alteration of the Earth system for a long period (Vitousek et al., 1997). Population in the Autonomous Region has increased rapidly from 1960 (1.2 million) to 1990 (2.2 million) (Chinese national statistics reports), contributing to both urbanization and changing landscape. For instance, Lhasa, the capital of the Tibet Autonomous Region, has grown 2400\% in the last 50 years (Du et al., 2004). Zou et al. (2002) found from observational data that desertified land is about $17.03 \%$ of the Tibet Autonomous Region's total land, and has been always mainly found in densely populated regions. Desertification on the TP most likely resulted from human-induced LUC (Zou et al., 2002).

Quantitative evaluation of climate changes by LUC is very difficult because long term meteorological and land surface observational data are not available. A further

\section{a) Current Land cover}

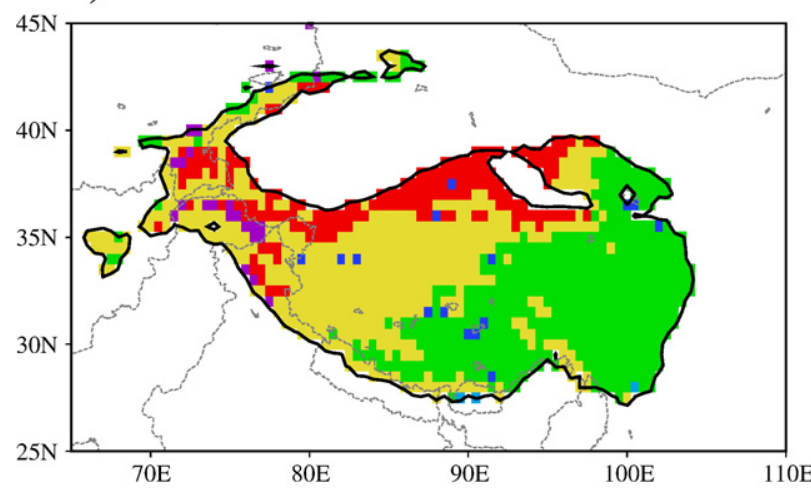

complication is that the land-atmosphere interactions are highly nonlinear. An approach to overcoming these difficulties is to utilize regional climate models (RCM) and global circulation models (GCM) in the study of LUC/climate change interactions (Suh and Lee, 2004). GCMs have long been used to study the TP, e.g. the comparison of climates under conditions with and without topography of the Tibetan Plateau (e.g. Murakami, 1958; Manabe and Terpsta, 1974; Broccoli and Manabe, 1992; Liu and Yin, 2002) although it is known that climatic modeling of the TP is especially difficult because of the steep orographic profile and heterogeneous surface conditions Cole et al., 1994). All GCMs involved in the AMIP (Gates et al., 1999), AMIP II, and CLIVAR/ Monsoon GCM Intercomparison Project (Kang et al., 2002) have large systematic errors in simulating the mean Asian monsoon climate and circulation. With model development, the performances of GCMs to reasonably reproduce the seasonal mean monsoon precipitation and circulation in the magnitude and pattern of flow are improved although biases still exist (e.g. Rajendran et al., 2004). Evaluation of model performance in representing the mean circulation and surface climate, especially in Asian region are strongly recommended before assessing model results of sensitivity experiments.

\section{b) Potential Land cover}

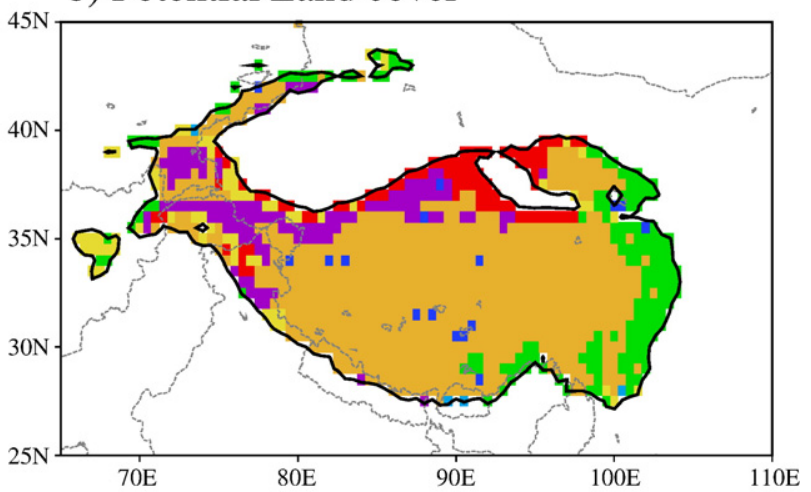

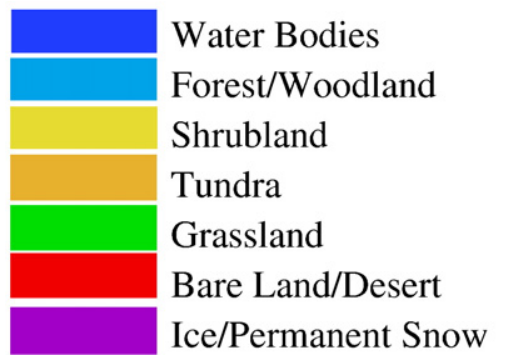

Fig. 2. Dominant a)current, and b) “natural" non-anthropogenically-influenced land cover on the Tibetan Plateau at $0.5^{\circ}$ resolution. Data are obtained from the International Satellite Land Surface Climatology Project (ISLSCP) initiative II data collection. 
Table 1

Surface parameters for major land cover types on the Tibetan Plateau. It includes background surface albedo $\alpha$, surface roughness length due to vegetation $Z_{0}$, veg, fractional vegetation cover VGR, leaf area index (LAI) for the growing (g) and dormancy season (d) and the volumetric wilting point $f_{\text {pwp }}$ (subjected from Hagemann, 2002)

\begin{tabular}{llllllll}
\hline $\begin{array}{l}\text { Global } \\
\text { ecosystems } \\
\text { legend }\end{array}$ & $\begin{array}{l}\text { Albedo } \\
\alpha\end{array}$ & $Z_{0}$, veg & VGRg & VGRd & LAIg & LAId $f_{\text {pwp }}$ \\
\hline Water & 0.07 & 0.0002 & 0. & 0. & 0. & 0. & 0. \\
Shrubland & 0.2 & 0.1 & 0.44 & 0. & 1.5 & 0.1 & 0.50 \\
Tundra & 0.17 & 0.03 & 0.51 & 0. & 2.2 & 0.4 & 0.34 \\
Grassland & 0.16 & 0.03 & 0.9 & 0.1 & 4.5 & 0. & 0.49 \\
$\begin{array}{l}\text { Bare land } \\
\text { Ice/permanent }\end{array}$ & 0.28 & 0.005 & 0. & 0. & 0. & 0. & 0. \\
\multicolumn{1}{c}{ snow cover } & & 0.005 & 0. & 0. & 0. & 0. & 0. \\
\hline
\end{tabular}

In this study, a general atmospheric circulation model has been applied to investigate the impact of LUC on the $\mathrm{TP}$ on regional and global climate. We have specifically examined: 1) how human-induced LUC impact the local climate on the TP, 2) if the modeled climate changes correspond to the observed trends in recent decades, 3 ) if the local effects are transmitted to further regions, and 4) how transmitted effects affect the weather and climate in other regions. The paper is organized as follows: in Section 2, the model and experimental set-ups are introduced. In Section 3, model performance on seasonal mean circulation and surface climate are evaluated with observations and sensitivity study results are presented as well. Finally, a discussion of the results, possible implications as well as conclusions is given in Section 4.

\section{Model and experiments}

\subsection{Model introduction}

The most recent version of the Max Planck Institute for Meteorology atmospheric general circulation model,

\section{a) Current LAI}

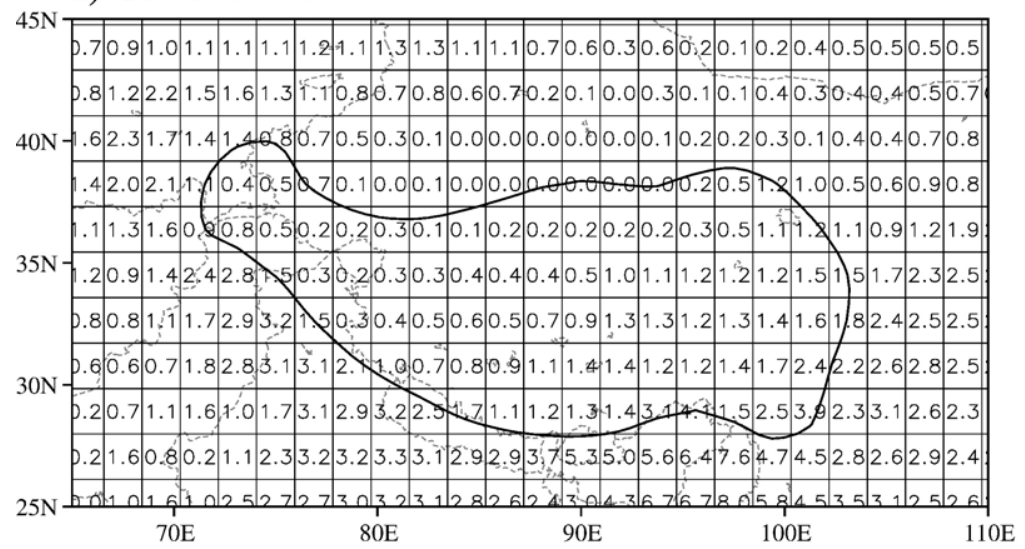

\section{b) Natural LAI}

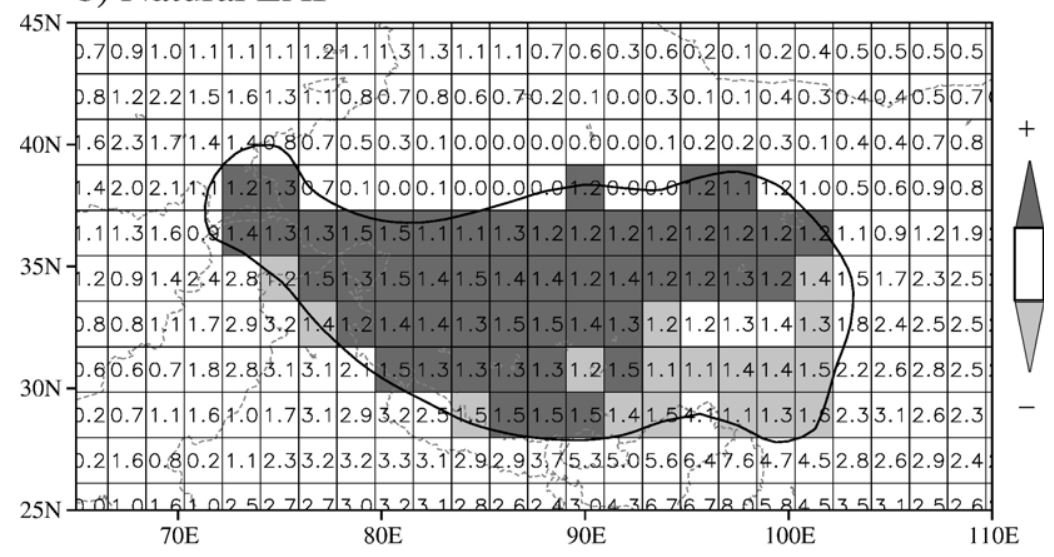

Fig. 3. Leaf area index (LAI;) and vegetation fraction (VGR, unit: \%) distribution on the Tibetan Plateau for current and natural scenarios. Grids are shaded where changes (current-natural) are greater than 0.01 or $1 \%$. 


\section{c) Current VGR}

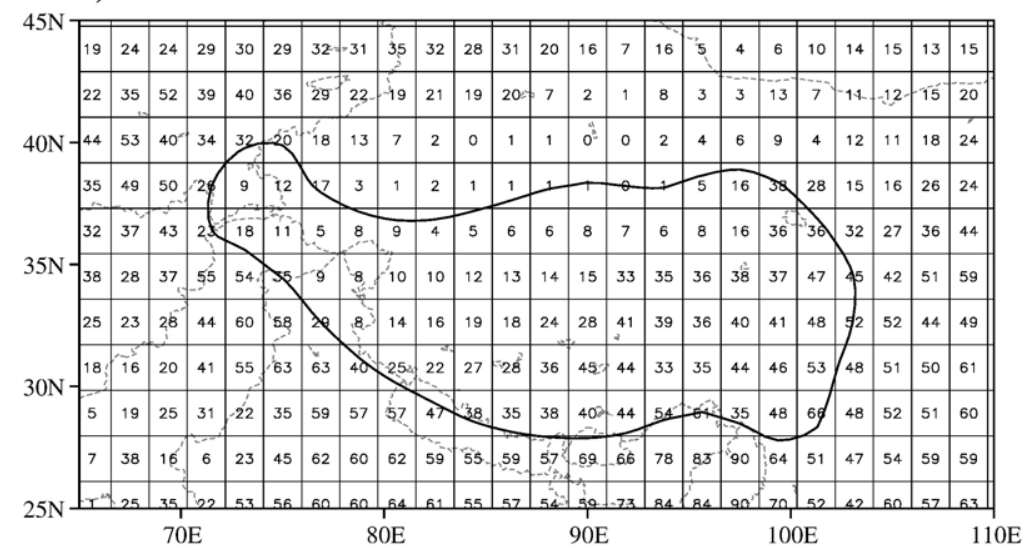

d) Natural VGR

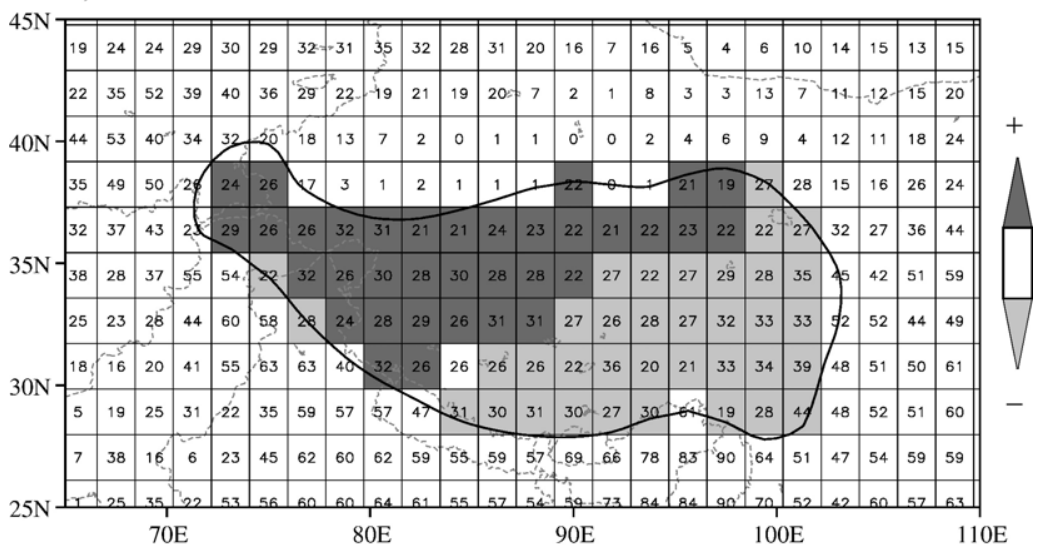

Fig. 3 (continued).

ECHAM5 (Roeckner et al., 2003) is used in this study. Duemenil Gates and Liess (2001) used the previous version ECHAM4 to study the sensitivity of the local and global climate during a full annual cycle to deforestation and afforestation in the Mediterranean region at T42 horizontal resolution. Their results agreed with other similar studies, but they also pointed out that the assumptions of vegetation cover and surface parameterization need to be improved in future studies. Compared to ECHAM4, ECHAM5 includes new surface processes, land surface data sets derived from satellite observations (Hagemann, 2002) and a seasonal cycle of vegetation

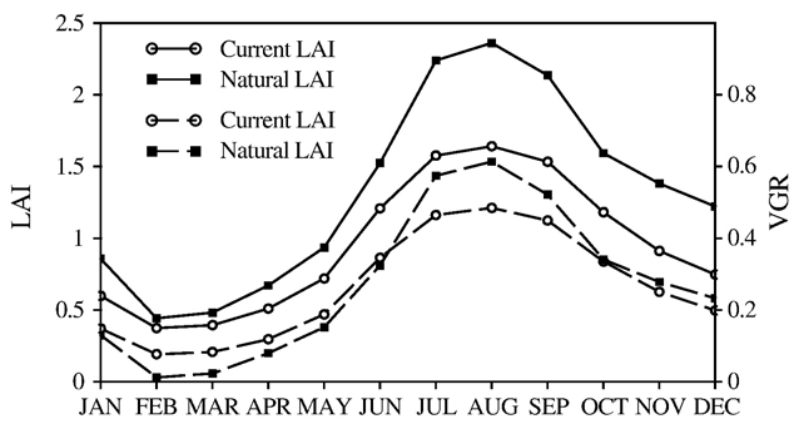

Fig. 4. Seasonal variations of the area averaged of Leaf Area Index (LAI, left) and vegetation fraction (VGR, right, unit: \%) on the Tibetan Plateau from the current and natural scenarios. 
Table 2

Observational (CPC Merged Analysis of Monthly Precipitation (CMAP); Climate Research Unit (CRU); Global Precipitation Climatological Project (GPCP)) and reanalysis (NCEP-DOE Atmospheric Model Intercomparison Project (AMIP II) Reanalysis (NCEP-R2)) datasets used with monthly precipitation $(P), 2-\mathrm{m}$ temperature $(T)$, zonal wind $(U)$, meridional wind $(V)$, and geopotential height $(H)$

\begin{tabular}{lllll}
\hline Dataset & Parameters & $\begin{array}{l}\text { Horizontal } \\
\text { resolution }\end{array}$ & References & Source \\
\hline CMAP & $P$ & $2.5^{\circ} \times 2.5^{\circ}$ & Xie and Arkin, 1997 & http://www.cdc.noaa.gov/cdc/data.cmap.html \\
CRU & $P ; T$ & $0.5^{\circ} \times 0.5^{\circ}$ & New et al., 2002 & http://www.cru.uea.ac.uk \\
GPCP & $P$ & $2.5^{\circ} \times 2.5^{\circ}$ & Adler et al., 2003 & http://wf.ncdc.noaa.gov/oa/wmo/wdcamet-ncdc.html \\
NCEP-R2 & $T ; U ; V ; H$ & $2.5^{\circ} \times 2.5^{\circ}$ & Kanamitsu et al., 2002 & $\mathrm{http} / /$ wesley.ncep.noaa.gov/products/wesley/reanalysis $/ \mathrm{kana} / \mathrm{reanl} 2-1 . \mathrm{html}$ \\
ERA40 & $T ; U ; V ; H$ & $\mathrm{~T} 159\left(0.75^{\circ}\right)$ & Simmons and Gibson, 2000 & $\mathrm{http} / /$ www.mad.zmaw.de \\
\hline
\end{tabular}

ratio and leaf area index, which may have detectable impact on the simulation of the seasonal cycle of precipitation and evaporation (van den Hurk et al., 2003).

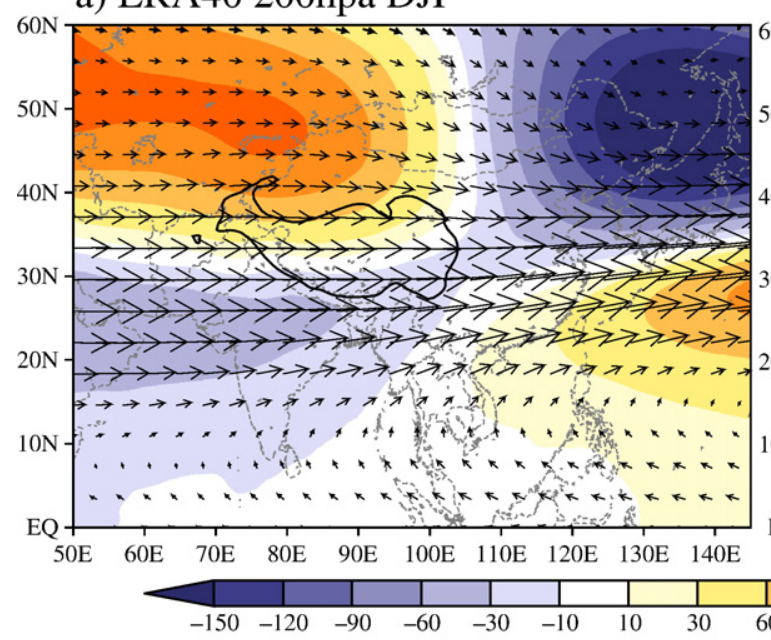

Additionally, a sub-grid scale orographic parameterization developed by Lott and Miller (1997) and Lott (1999) is implemented in ECHAM5 aiming to represent the

\section{b) ECHAM5 Current 200hpa DJF}

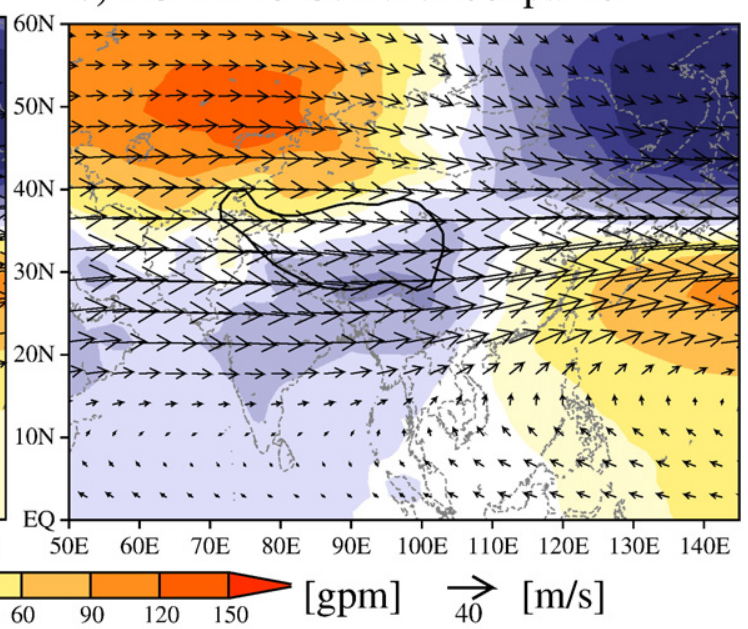

c) ERA40 200hpa JJA

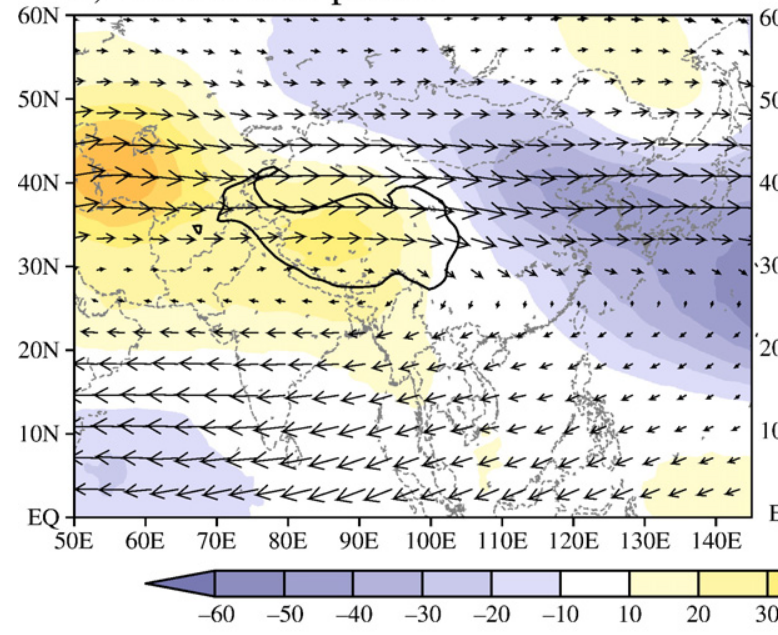

d) ECHAM5 Current 200hpa JJA

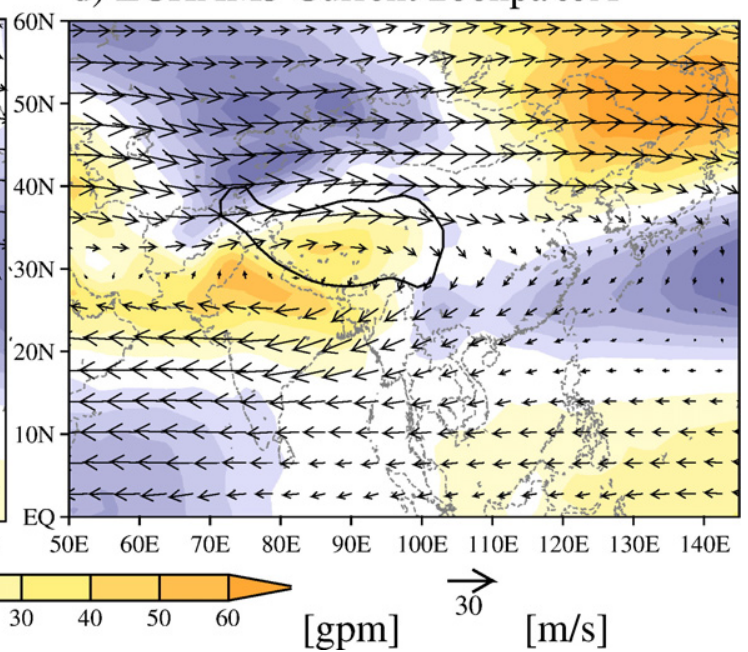

Fig. 5. Wind circulation and geopotential height eddy derived from the zonal mean of the whole region $\left(50^{\circ} \mathrm{E}-140^{\circ} \mathrm{E}\right)$ at $200 \mathrm{hpa}$ from ERA40 (up) and ECHAM5 current simulations (below) for JJA (left) and DJF (right). The thick black contour line shows the Tibetan Plateau. Map are shown in grey contours. 
effects of orographic variations on smaller scales than the typical horizontal resolution of a climate model (Roeckner et al., 2003). Lott (1999) concluded that such parameterization schemes are beneficial to GCMs by decelerating significantly the low level flow, which is expected to improve the performance on mountainous region, like the TP.

A hybrid 19 level coordinate system is used in the vertical direction: the sigma system at the lowest model levels gradually transforms into a pressure system in the lower stratosphere. Roeckner et al. (2004) concluded that some individual processes, like the Indian and East Asian monsoon evolution, are better captured by ECHAM5 at higher horizontal resolution, although there is little evidence for convergence to a more realistic climate state at higher resolution. Given the restriction of computational resource, the simulations in this study are performed at $\mathrm{T} 63$ resolution, corresponding to a grid size of about $1.875^{\circ}$ in longitude and latitude. In the Tibetan Plateau region, this is equal to about $150 \mathrm{~km}$ in the longitudinal and $200 \mathrm{~km}$ in the latitudinal directions. While some of the realism of summer precipitation in terms of intensity of single events is missing in such a coarse resolution GCM, the use of the global model enables us to see global climate sensitivity of the model simulation to the land use/land cover change, to observe the propagation of atmospheric effects from the area where the local changes were applied and may reveal global teleconnections. a) ERA40 500hpa DJF

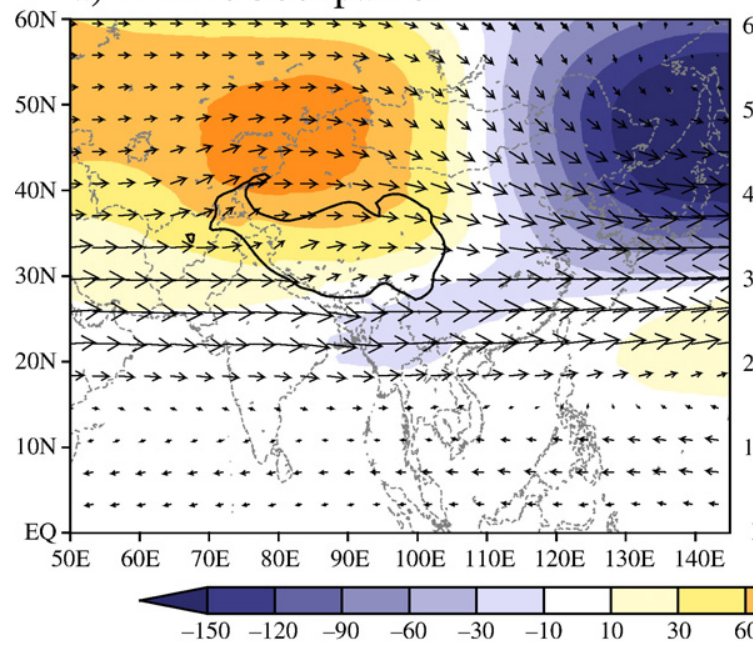

\section{b) ECHAM5 Current 500hpa DJF}

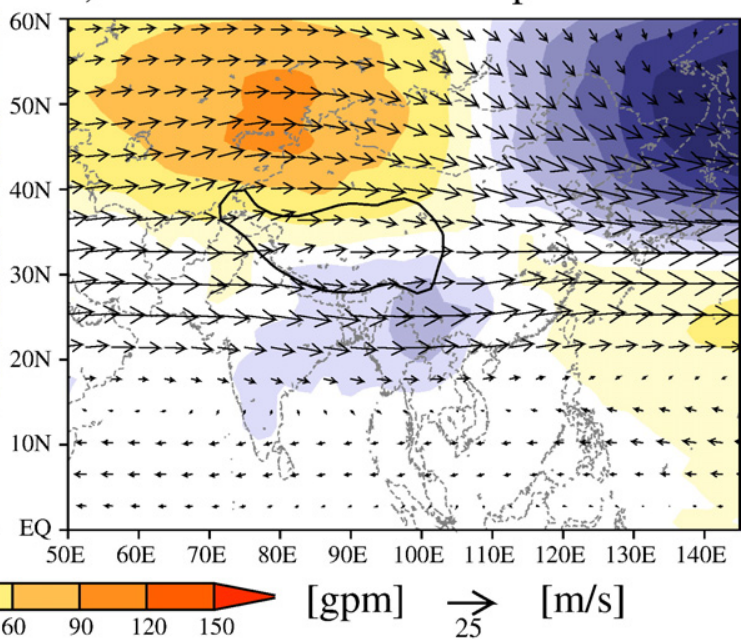

c) ERA40 500hpa JJA

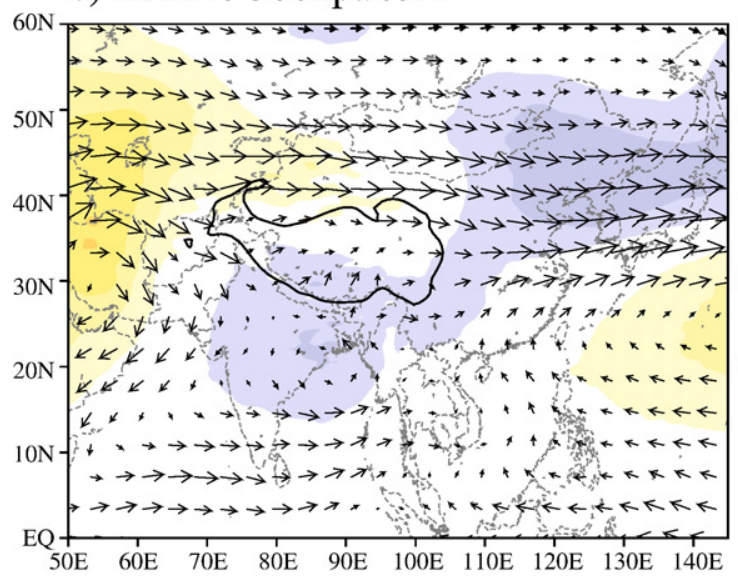

d) ECHAM5 Current 500hpa JJA

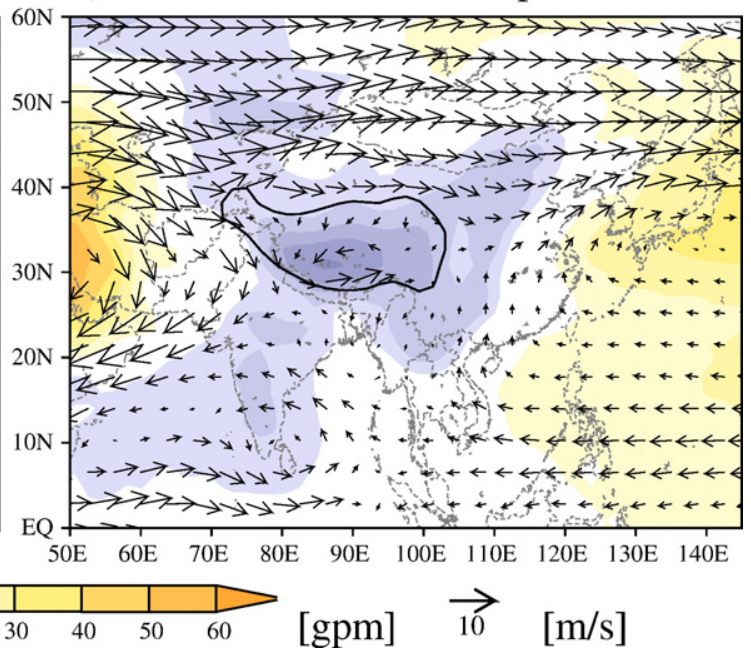

Fig. 6. Same as Fig. 5, but for 500 hpa. 


\subsection{Experiment design}

Assessment of land use changes on the TP is extremely difficult due to the scarcity of observational data at both spatial and temporal scales. Remote sensing data sets are very powerful tools to evaluate the LUC for this region (Suh and Lee, 2004). Fig. 2a shows the current land cover type also obtained from the International Satellite Land Surface Climatology Project (ISLSCP) initiative II data collection (Loveland et al., 1999). Currently, the TP has a western shrubland and an eastern grassland part, with bare land appearing at the northern boundary. This vegetation distribution responds to the dry west and wet east distribution of moisture (Ye and Gao, 1979).
The "natural" distribution of vegetation types in a region should be in equilibrium with climate, water and nutrient availability, but, in reality, the distribution of vegetation is always modified by anthropogenic influences. Reconstruction of the non-anthropogenically influenced vegetation other than by modeling is rather difficult. However, it is feasible to specify the equilibrium climate vegetation, called Potential Natural Vegetation (PNV), which represents the vegetation cover that would most likely exist now in equilibrium with presentday climate and natural disturbance, in the absence of human activities (Ojima et al., 2000). The PNV data used in this paper is based on the ISLSCP initiative II data collection and it is not necessarily representative of prehuman settlement vegetation in non-human dominated a) ERA40 850hpa DJF

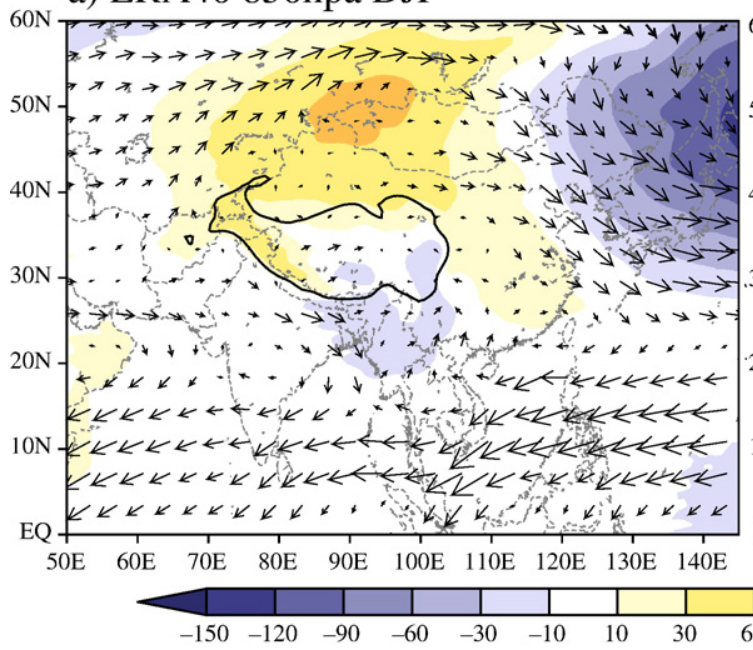

b) ECHAM5 Current 850hpa DJF

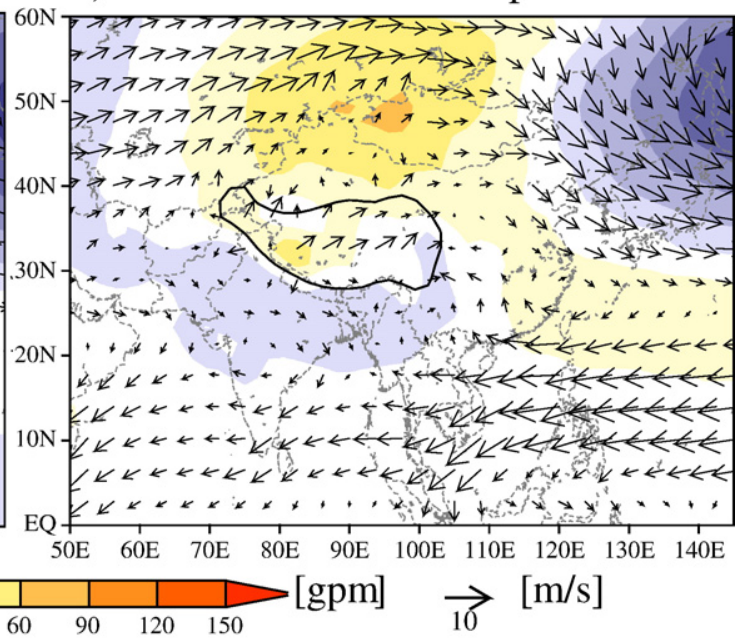

c) ERA40 850hpa JJA

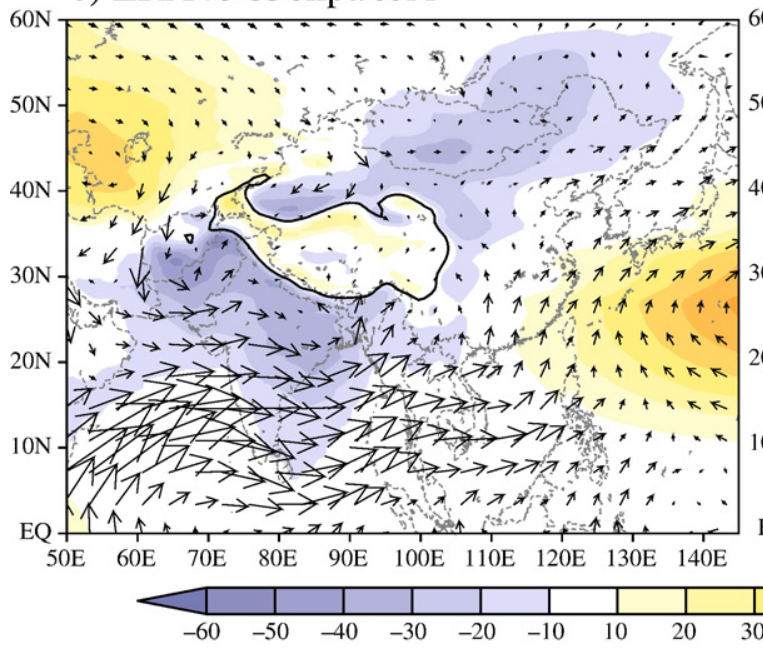

d) ECHAM5 Current 850hpa JJA

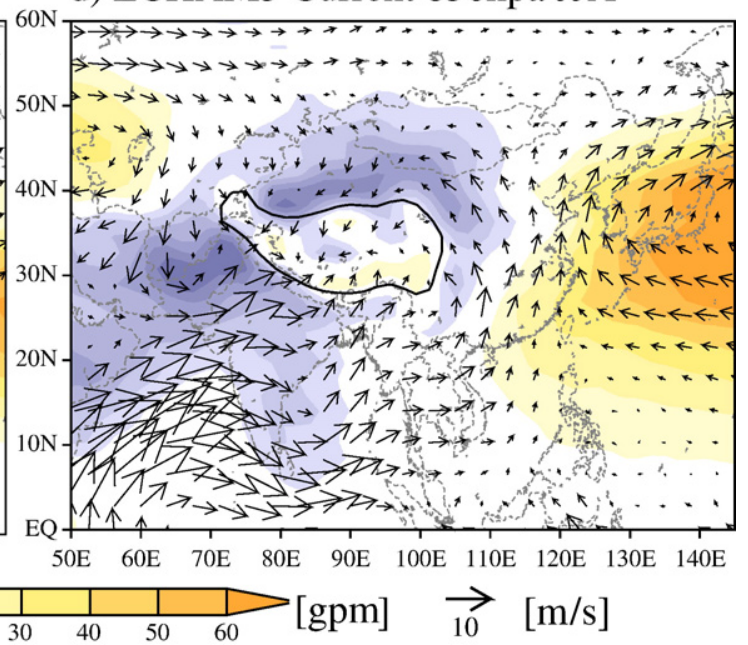

Fig. 7. Same as Fig. 5, but for 850 hpa. The black shaded region shows the TP. 
regions, such as the TP (Ramankutty and Foley, 1999). Without human influences and with present-day climate, almost the whole TP would be covered by tundra (Fig. 2b). Compared with the current land cover (Fig. 2a), a much smaller region (Fig. 2b) is covered with grassland on the east part and less bare land on the northern boundary. Ice and permanent snow would be located in the northwest part of the TP. More accurate estimates of the land cover changes on the TP should be developed. However, the current estimates enable us to begin exploring the issues addressed in the modelling experiments conducted in this study.

The control experiment run called "current scenario" used a standard ECHAM5 simulation to represent the "real" climate system with the modern day land cover. The sensitivity experiment, called "natural scenario",

\section{a) CRU}

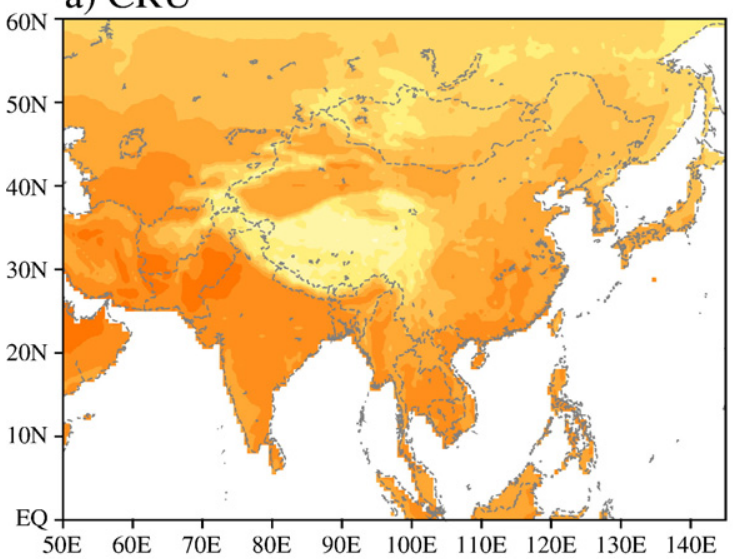

c) NCEP-R2

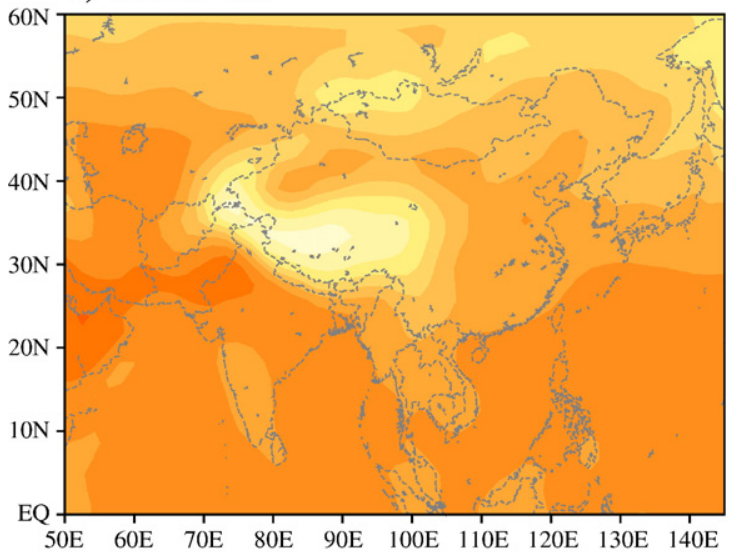

replaced the current land cover on the TP (Fig. 2a) with the natural land cover without anthropogenic influences (Fig. 2b). In ECHAM5, vegetation is characterized by the ratio of the leaf area to the projection area and the fractional area covered by plants (Leaf Area Index (LAI) and Vegetation Fraction (VGR), respectively; see Hagemann (2002) for more details). The land surface parameters are allocated to each ecosystem type based on the $1-\mathrm{km}$ resolution global land cover characteristics database derived from 1-km Advanced Very High Resolution Radiometer (AVHRR) data (available from U.S. Geological Survey, 2001). Table 1 lists the main surface parameters applied in ECHAM5 for major land cover types on the TP. For snow-free land surfaces, the annual mean background albedo derived from satellite data only depends on the ecosystem type. Fig. 3 shows the yearly

\section{b) ERA40}

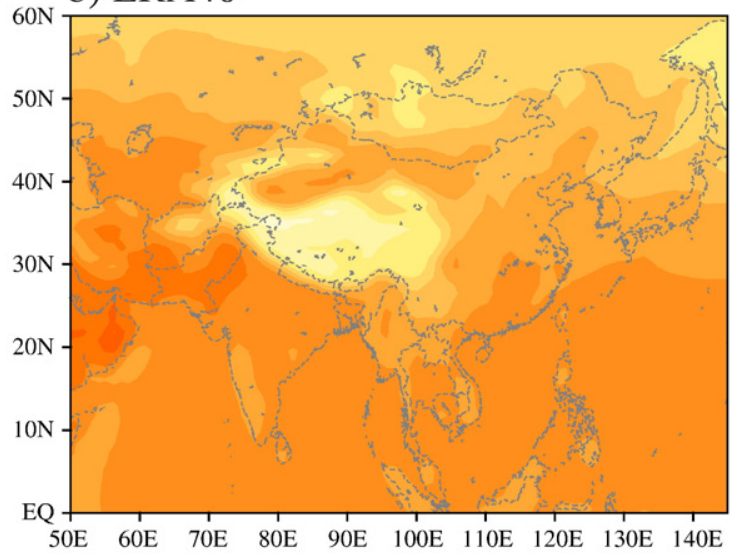

d) ECHAM5 Current

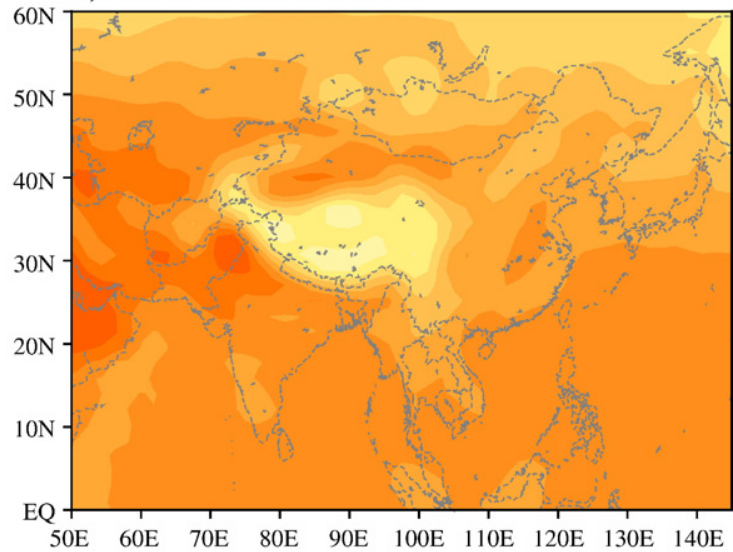

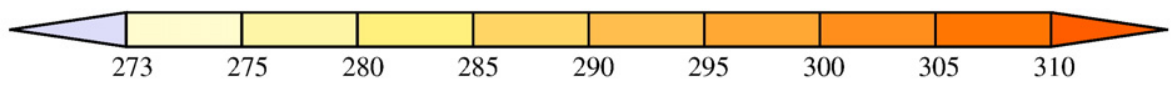

Fig. 8. Intercomparison of summer (JJA) 2-m air temperature from a) CRU, b) ERA40, c) NCEP-R2, and d) ECHAM5 current simulation. Data information listed in Table 1. 
means of LAI and VGR used in the current and natural experiment, respectively. In the central and western part of the TP, current LAI and VGR are lower than the natural case, and they are higher mainly in the southeastern part. High LAI values correspond to high canopy conductance values, resulting in a relatively large portion of available energy being used for evapotranspiration (van den Hurk et al., 2003). The annual cycle of LAI and VGR (Fig. 4) shows that the main differences occur in the boreal summer. In the winter, current VGR is larger than the natural one, while current LAI is always smaller than natural LAI.

Both experiments are integrated for 22 years, driven with climatological global sea surface temperature (SST) and sea ice averaged over the period 1979-1988 to eliminate additional inter-annual variability. The atmospheric variability represented in such integrations is generally less

a) CRU

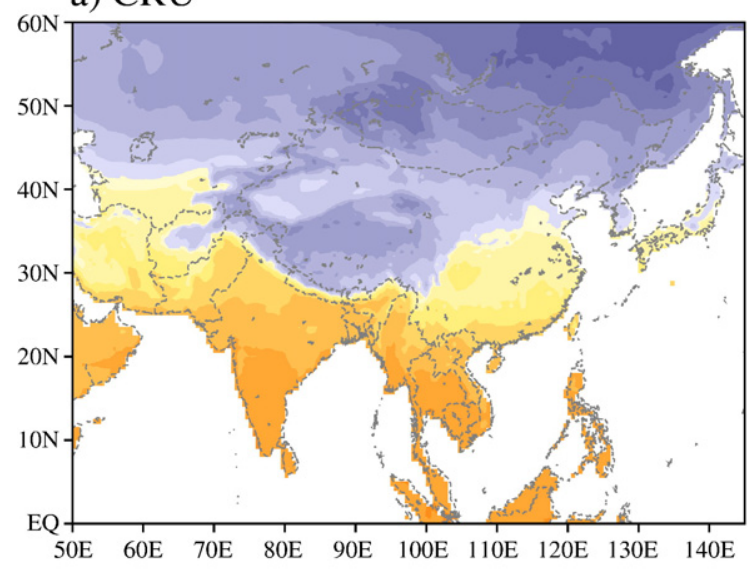

c) NCEP-R2

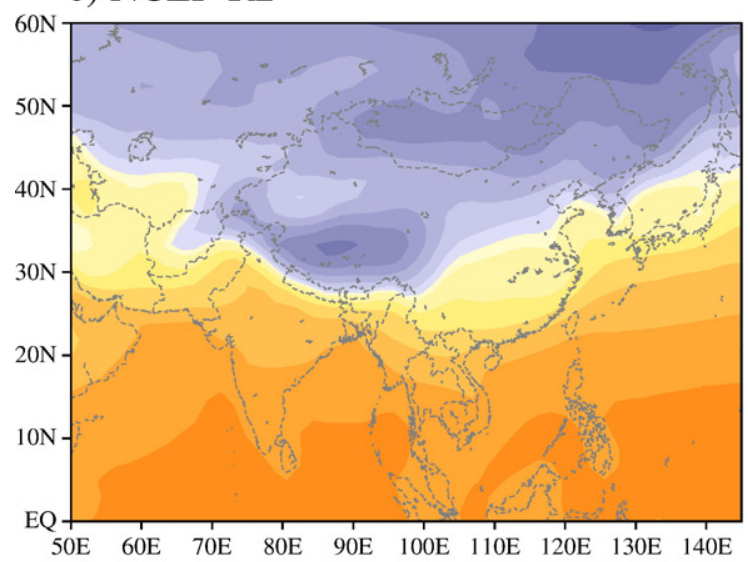

than that in simulations with inter-annually varying boundary conditions of SST and sea ice (Bengtsson et al., 1996). The results presented in this paper are the mean values over the last 10 years of the model simulations, discarding the first 12 years to eliminate the effects of model spin-up. In this paper, we restricted ourselves on the seasonal mean characteristics. The calendar monthly mean is calculated by a normal mean of the corresponding months of the 10 years. To evaluate the model performances, especially for the TP and its vicinity, results from the control run are compared with several observational datasets, listed in Table 2. Kistler et al. (2001) named the period from 1979 to present as "modern satellite" era, and also pointed out that the reanalysis data are most reliable in this period. Thus in this study, the present climate to evaluate the ECHAM5 simulation is calculated from all the datasets as the 20 years mean from 1980 to 2000 . The calendar

\section{b) ERA40}

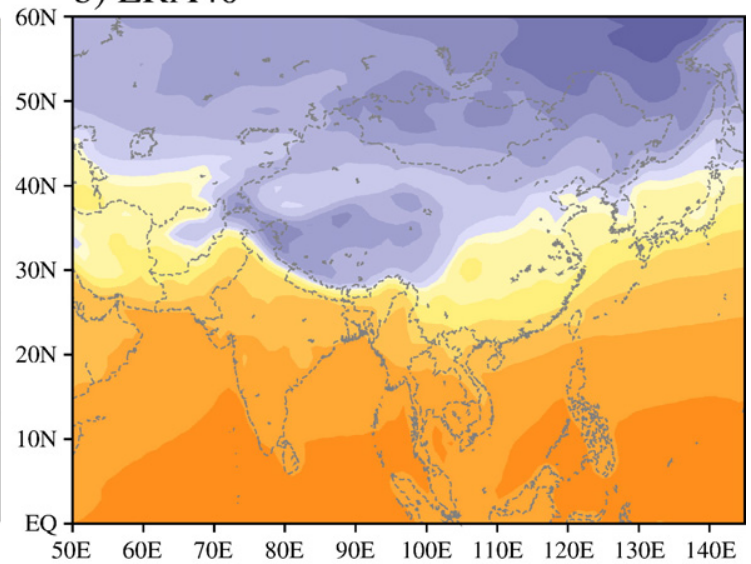

d) ECHAM5 Current

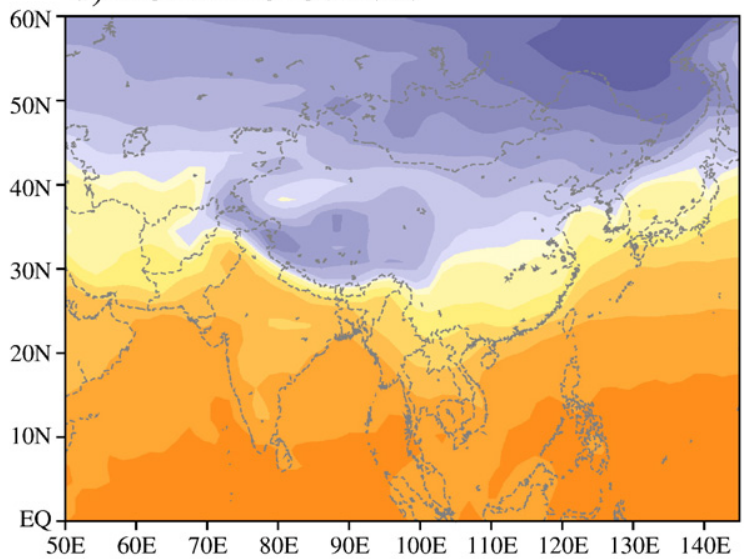

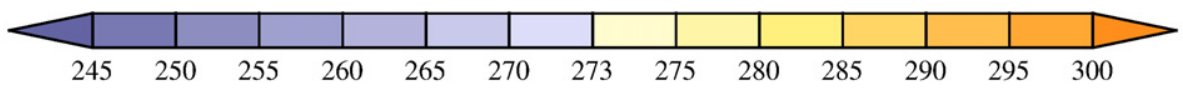

Fig. 9. Same as Fig. 8, but for DJF. 
monthly mean is calculated with the normal mean of the corresponding months of the 20 years.

The natural vegetation cover simulation is compared with the current vegetation cover simulation to show the effects of land use change on the regional and global climate. In this paper, we restricted ourselves to showing the comparisons of means. Since both experiments start from the same initial condition except the land cover on TP and the integrations are short, the results from the two experiments are not independent from each other. Therefore the $t$ test, also known as Student's $t$ test, is not appropriate for testing the null hypothesis that the change of land cover on the TP has no effect on the state of the modeled atmosphere (von Storch and Zwiers, 1999). von Storch and Zwiers (1999) proposed a socalled 'Paired Difference Test' to test the null hypothesis

a) $\mathrm{CRU}$

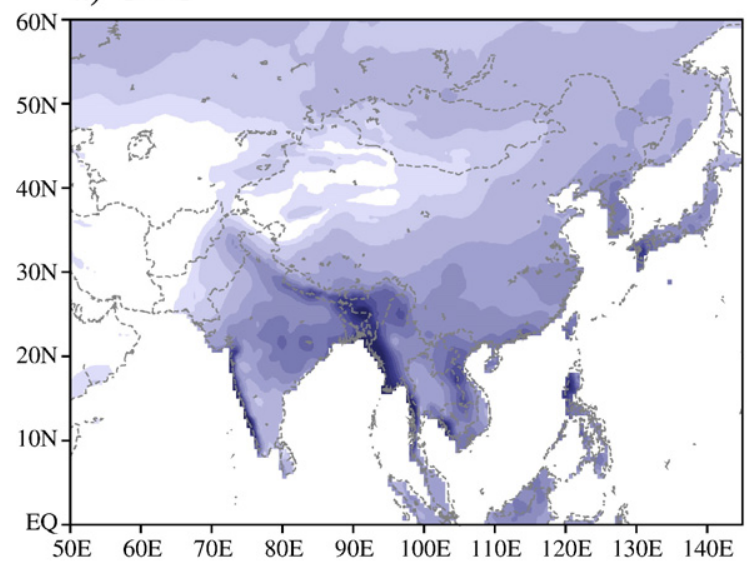

c) GPCP

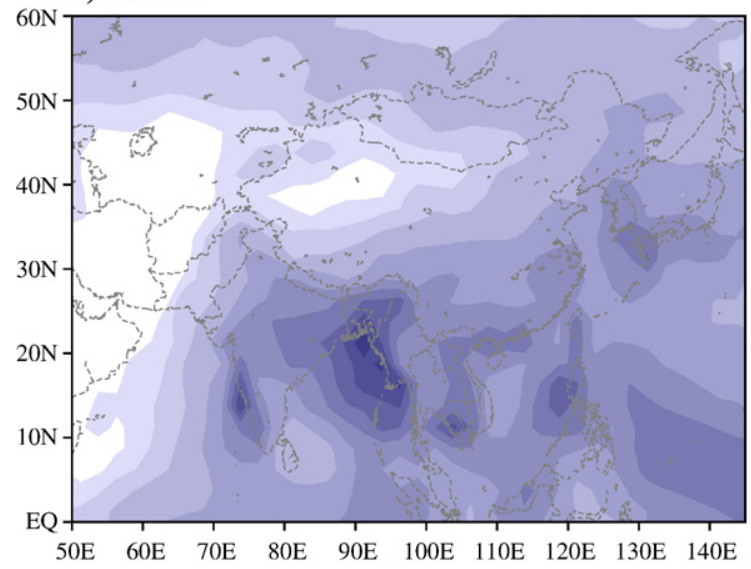

that the mean difference is zero using a one-sample $t$ test. The distributional assumptions are that the differences have a normal distribution and that all the differences come from the same distribution. This method is applied to each grid point to assess statistical significance. At the 5\% (10\%) significance level, one would expect $5 \%(10 \%)$ of the grid points to show statistically significant differences merely by chance. However, physical insight is required to ascertain the statistical significance is physical significance (von Storch and Zwiers, 1999). Statistical significance is determined using seasonal (December, January, February; March, April, May; June, July, August; September, October, November) or annual rather than monthly averages to include less of the year-to-year variability (Bonan, 1997). Each year of model output represents one seasonal or

\section{b) CMAP}

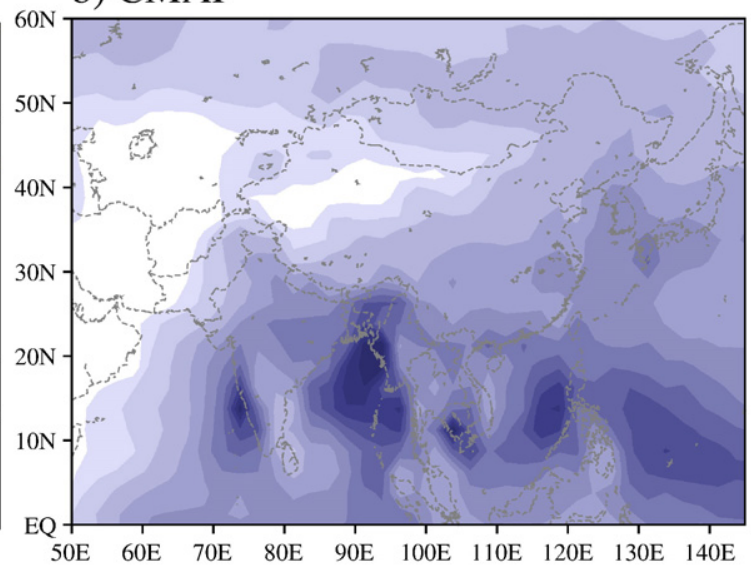

d) ECHAM5 Current

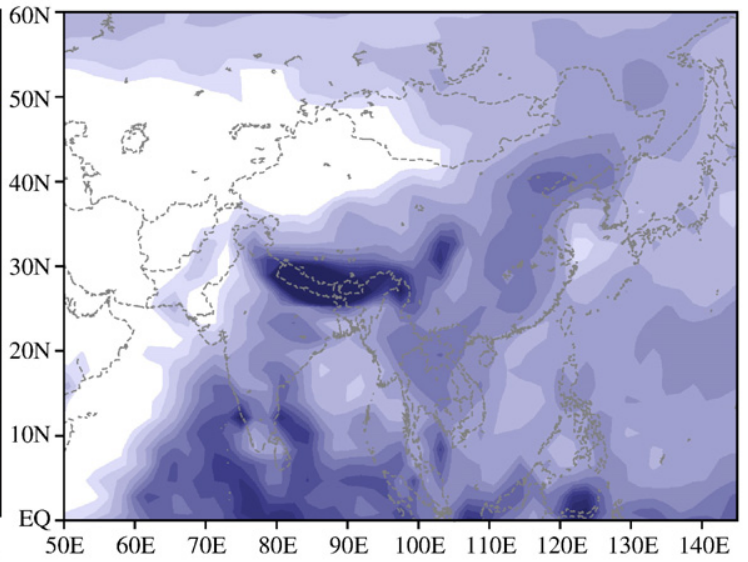

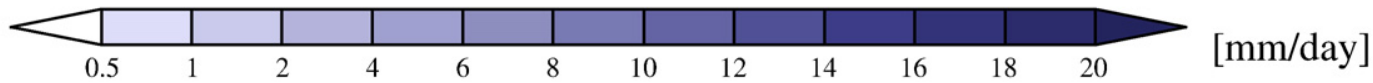

Fig. 10. Intercomparison of summer (JJA) monthly precipitation from a) CRU, b) ERA40, c) NCEP-R2, and d) ECHAM5 current simulation. Data information listed in Table 1. 
annual 'sample'. The analyzed duration of both experiments ( 10 years) means that there are only 9 degrees of freedom when testing for the difference between two means with the method applied here.

\section{Results}

\subsection{ECHAM5 current scenario}

Evaluation in the Asian region is discussed in detail focusing on the summer (June July August (JJA)) rainy season and the winter (December January February (DJF)) season. Wind and geopotential height are "type A" variables in reanalysis data, which are generally strongly influenced by the available observations and

\section{a) $\mathrm{CRU}$}

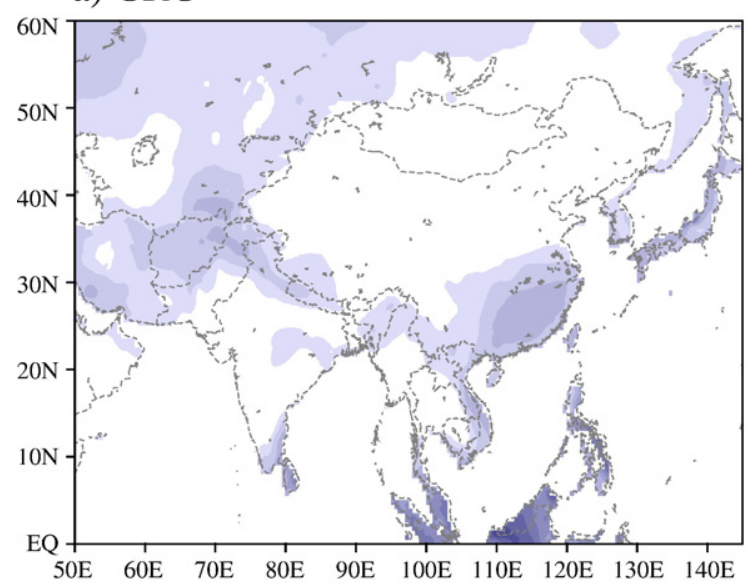

c) GPCP

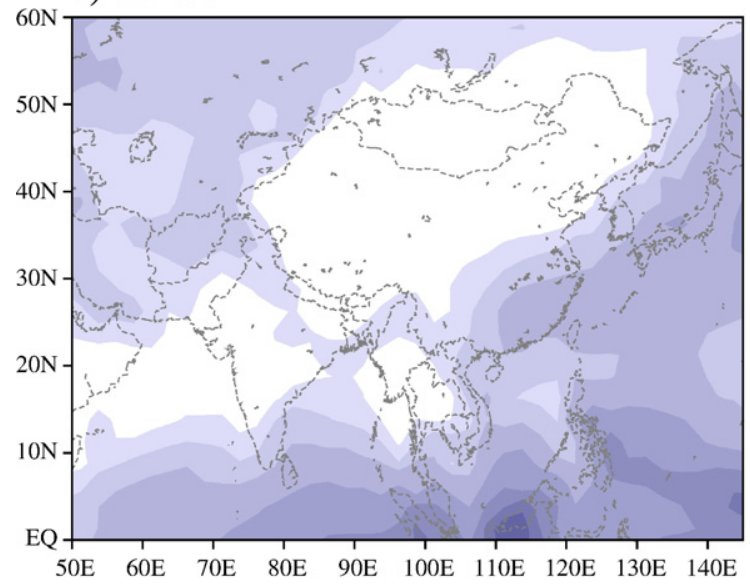

are therefore the most reliable products of the reanalysis (Kistler et al., 2001). Fig. 5 shows a comparison of wind and geopotential height eddy at $200 \mathrm{hpa}$ between ERA40 and the ECHAM5 current scenario we conducted. The NCEP R2 data is very similar to the ERA40, so we have only shown the ERA40 dataset. ECHAM5 reproduces the major meteorological features: the dominant westerlies move northward from winter to summer and an anticyclone centered on the TP appears in summer. There are also discrepancies between the model simulation and the observations. The simulation shows stronger wind speed in both seasons and unrealistic pressure systems in summer: too high over India and northeast China while too low over the Indian Ocean and the northwest side of the TP. Differences may

\section{b) CMAP}

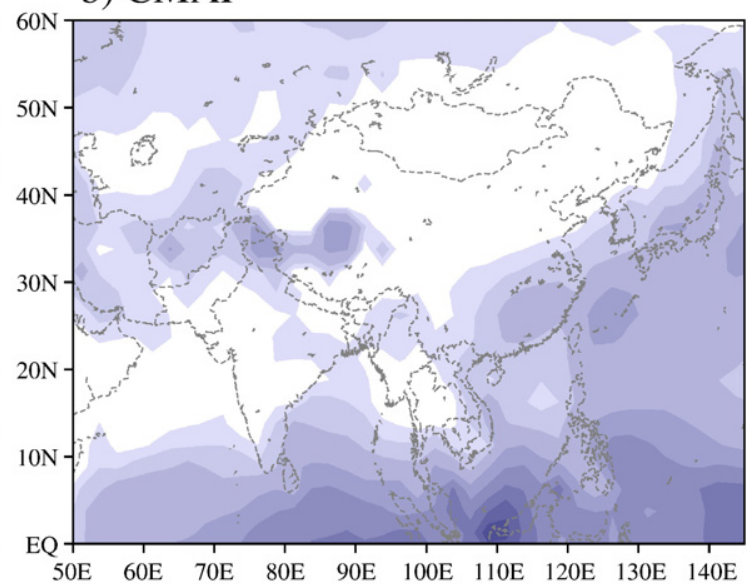

d) ECHAM5 Current

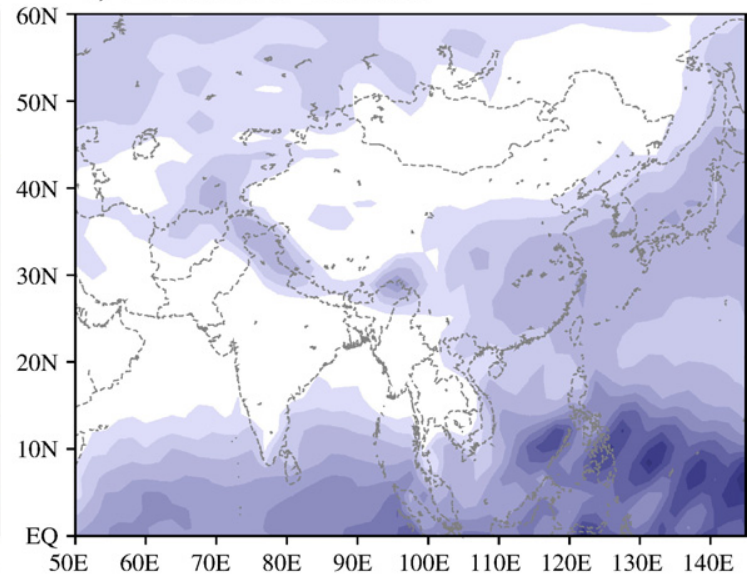

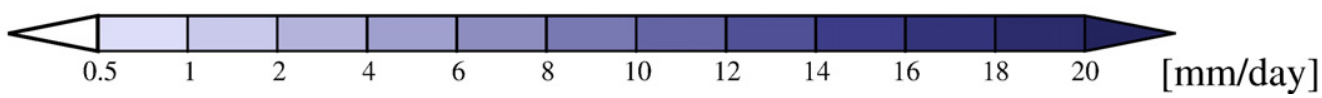

Fig. 11. Same as Fig. 10, but for DJF. 
be decreased if more realistic SSTs are applied, like in AMIP experiments, rather than the climatological mean values that are used in current simulation. Figs. 6 and 7 are the same as Fig. 5 but for the 500 hpa and 850 hpa levels, respectively. The model reasonably simulates the large-scale features. The westerly jet still dominates the circulation at $500 \mathrm{hpa}$ in winter similar to the $200 \mathrm{hpa}$ level and it also shifts from the south of the TP to the north in summer. A Low is located over the TP and its vicinity at 500 hpa and 850 hpa level, while it is a High at $200 \mathrm{hpa}$. This is a very special pressure system on the
TP in summer. At 850 hpa, the wind follows the landmass distribution more closely. In summer it blows from the Indian Ocean to India and from the Pacific Ocean to the East Asian continent, laden with warm and moist air mass, thus producing summer monsoon rainfall in these regions. In the winter, the wind blows from the central Eurasian continent to East Asia, transporting cold and dry air. Such circulations produce the winter monsoon for these regions. The model simulates well the deep trough centered at $140^{\circ} \mathrm{E}, 50^{\circ} \mathrm{N}$ existing from $850 \mathrm{hpa}$ to $200 \mathrm{hpa}$ in winter, that disappears in summer and

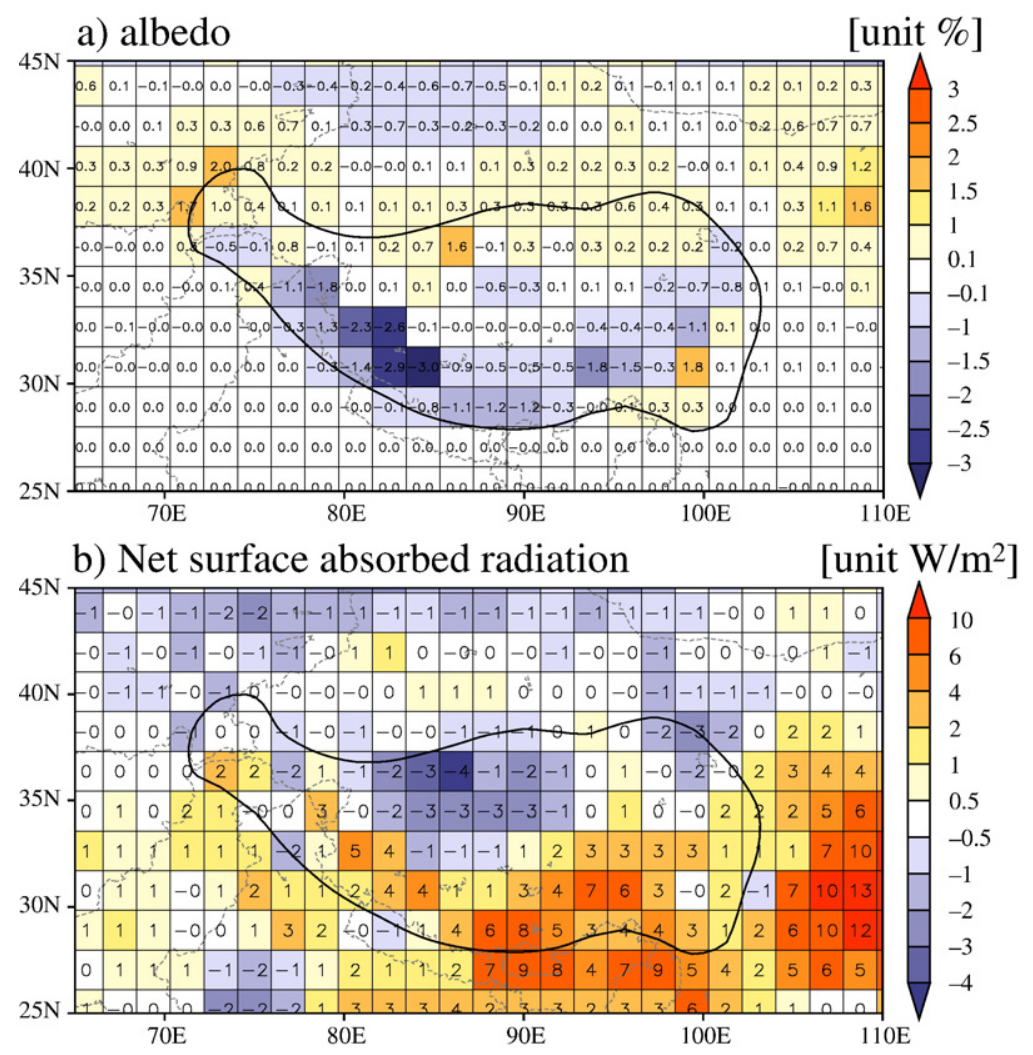

c) $2 \mathrm{~m}$ Temperature

[unit:K]

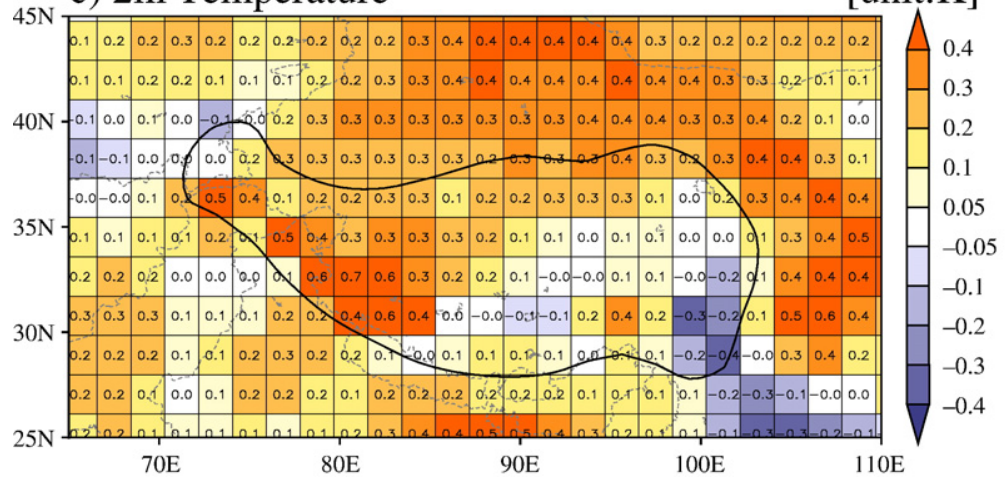

Fig. 12. The difference (current minus natural) of a) albedo, b) net surface solar radiation, c) 2-m temperature, d) soil moisture, e) evaporation, f) precipitation. 
d) Soil moisture

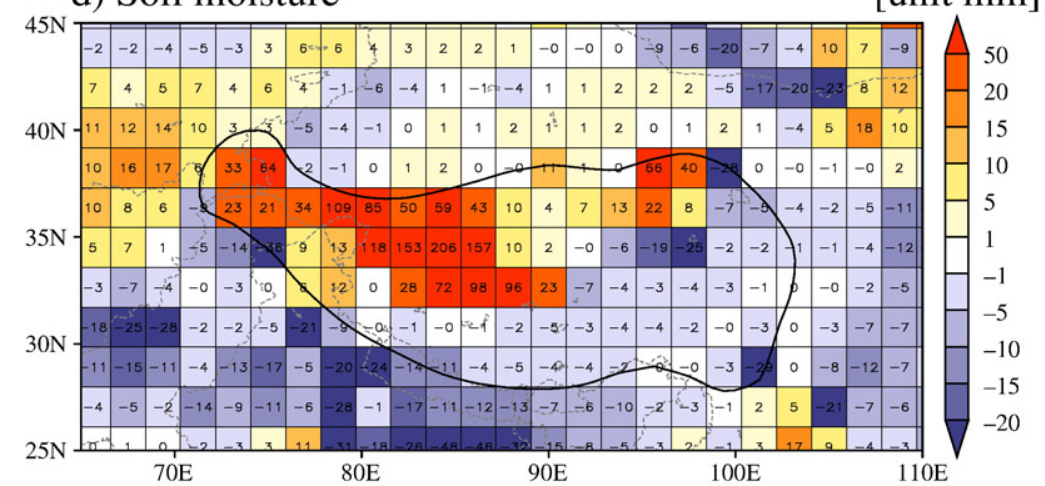

e) evaporation

[unit $\mathrm{mm} /$ day]

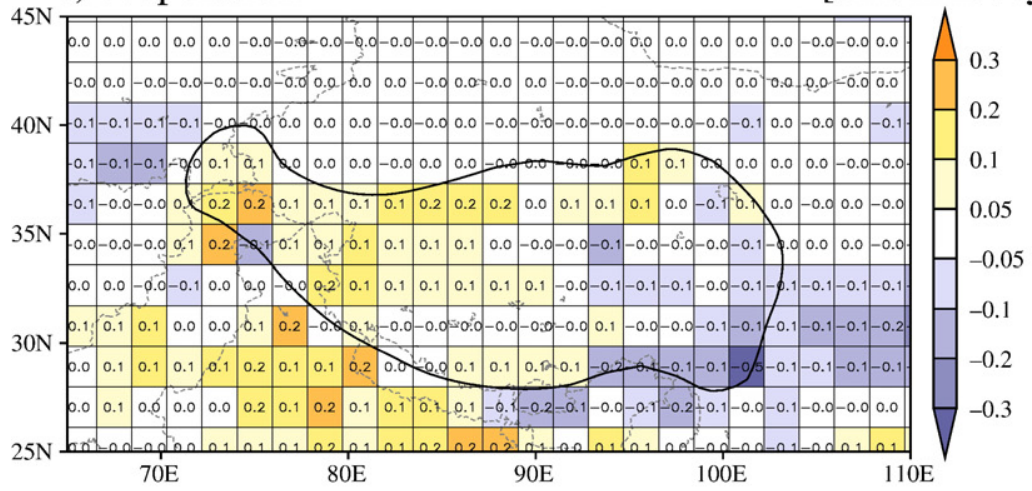

f) precipitation

[unit:mm/day]

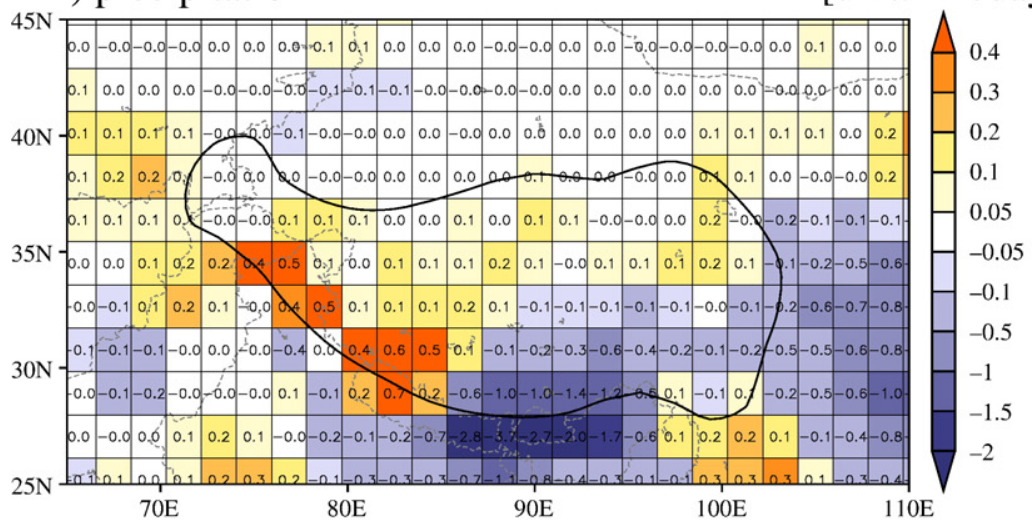

Fig. 12 (continued).

becomes a high. There is always a small trough in the lower mid-troposphere that moves from the east of India in winter to the west of India in summer and gets stronger. In general, ECHAM5 realistically reproduces the major features of the circulation system in this region with somewhat higher wind speed and least realistic geopotential heights in summer. The model performs better at lower troposphere and in winter.

Figs. 8 and 9 present the 2-m air temperature in summer (JJA) and in winter (DJF) from observations
(CRU), reanalysis data (ERA40 and NCEP-R2), and from our ECHAM5 current simulation, respectively. For the ERA40 and NCEP-R2 reanalysis data, 2-m temperature is a "type B" variable, partly influenced by the model parameterization, and is therefore less reliable (Kistler et al., 2001). Compared with station measurements where grid cells contain at least four stations, the reanalysis temperatures from ERA40 are consistently lower, by as much as $7{ }^{\circ} \mathrm{C}$ (Frauenfeld et al., 2005). On the $\mathrm{TP}$, such a topographically complex, data-sparse 
Table 3

Summary of annual mean difference between current and natural scenarios for the area averaged parameters over the TP including the leaf area index (LAI), fraction of vegetation (VGR), surface albedo, geopotential height ( $H$, unit: $\mathrm{m}$ ) and atmospheric temperature $(T$, unit: $\mathrm{K})$ at $200 \mathrm{mb}$ and $500 \mathrm{mb}$, daily precipitation $(P$, unit: $\mathrm{mm})$, evaporation $(E$, unit: $\mathrm{mm})$, and atmospheric temperature at $2 \mathrm{~m}\left(T_{2 \mathrm{~m}}\right.$, unit: $\left.\mathrm{K}\right)$

\begin{tabular}{lcccccccrrr}
\hline & \multicolumn{1}{c}{ LAI } & \multicolumn{1}{c}{ VGR } & \multicolumn{1}{c}{ Albedo } & \multicolumn{1}{c}{$H_{200}$} & $H_{500}$ & \multicolumn{1}{c}{$T_{200}$} & \multicolumn{1}{c}{$T_{500}$} & $P$ & $\mathrm{E}$ \\
\hline Current scenario & 0.95 & 0.262 & 0.2798 & 12,247 & 5776.1 & 219.984 & 263.692 & 3.05 & -1.24 & 271.70 \\
Natural scenario & 1.32 & 0.273 & 0.2830 & 12,241 & 5774.1 & 219.734 & 263.571 & 3.08 & -1.26 & 271.53 \\
Difference & -0.37 & -0.011 & -0.0002 & 6 & 2.0 & 0.25 & 0.12 & -0.03 & 0.02 & 0.17 \\
\hline
\end{tabular}

area, it is not surprising to see the spatial difference among ERA40, NCEP R2 and CRU data, further exaggerated by the different horizontal resolutions among them. To better represent the real surface parameters on the TP, we suggest that higher horizontal resolution data sets that resolve the steep topographic variations should be developed in the future. In general, ECHAM5 simulates well the major patterns and temperatures year round. During winter, 2-m temperatures on the TP are below $0{ }^{\circ} \mathrm{C}$ on the entire plateau, with summer values of only $0{ }^{\circ} \mathrm{C}$ in the west and about $10^{\circ} \mathrm{C}$ in the east. ECHAM5 also reproduces well the heating contrast between landmass and ocean, which is generally considered to be the most important driving mechanism for the monsoon system (e.g. Webster et al., 1998).

ECHAM5 also reproduces well the summer monsoon rainfall belt from the Indian continent to southern China (Fig. 10), except too great (more than $20 \mathrm{~mm} /$ day) a rainfall at the south of the Himalayas in summer. This effect may be caused by too much convective rainfall parameterized by the model at that steep topographic barrier. ECHAM5 simulates very realistically the rain belt moving back to the Tropics in winter (Fig. 11). As mentioned in Section 1, almost all current GCMs have very large systematic errors in simulating the mean monsoon climate and circulation (Kang et al., 2002). Due to the uncertainties of the model related to the simulation of the Asian monsoon, the values of the monsoon rainfall produced by the model should be cited with high caution. This does not, however, obstruct this study, because our main aim is to qualitatively, not quantitatively, investigate the climatic response to the land use changes on the TP.

\subsection{ECHAM5 natural scenario}

One of the direct effects of LUC is the modification of surface albedo, and thus an influence on the surface absorbed solar radiation. In ECHAM5, for snow-free land surfaces, an annual mean background albedo derived from satellite data is allocated to the major ecosystems shown in Table 1 for the TP. For land surface, the grid-mean albedo depends on a number of parame- ters including fractional forest area, leaf area index, bare-soil land, snow albedo calculated as a linear function of surface temperature, and the fractional snow cover (Hagemann, 2002). Over water surfaces the albedo is set to a constant value of 0.07 . Fig. 12 shows the difference between the current and natural scenarios of a) albedo, b) net surface solar radiation, c) 2-m air temperature, d) soil moisture, e) evaporation, and f) precipitation. The current albedo is greater (less) in the north (south) of the TP compared to the natural one, and thus decreases (increases) the solar radiation absorbed by the surface. The modification of the radiation budget will change the surface fluxes and thus the local climate. Temperature is higher almost for the whole TP with its largest values in the west, mainly because there is more ice/snow covering these surfaces when assuming natural land cover. On average, the area averaged temperature of the TP increased by $0.17^{\circ} \mathrm{C}$ due to human induced land use change (Table 3 ).

Another direct effect of LUC on local climate is the modification of the local water cycle. The parameterization of soil hydrology in ECHAM5 comprises budget equations for the amount of snow on the surface, the amount of water intercepted by the vegetation, and the soil water storage. Only a maximum value of $10 \mathrm{~cm}$ is accessible for evaporation in the non-vegetated part of a grid point (bare soil). In the vegetated part the difference between actual soil moisture and the wilting point, assigned differently according to the type of vegetation (listed in Table 1; Hagemann, 2002), is accessible for evaporation. Fig. 12d-f shows more active water exchange in the west of the TP, with higher precipitation, soil moisture, and thus higher evaporation in the current scenario than in the natural one. In the east of the TP, the climate is modified in the opposite direction, with annual mean soil moisture content, evaporation and precipitation all decreased to different extents. The area average change of yearly mean precipitation on the TP is decreased by $9 \mathrm{~mm}$ (Table 3 ). It is interesting to see that precipitation is decreased dramatically to the south of the Himalayas. We do not yet know what mechanisms are contributing to the observed changes. The observed changes are not limited locally to the TP. To study the 
a) $200 \mathrm{hpa} \mathrm{DJF}$

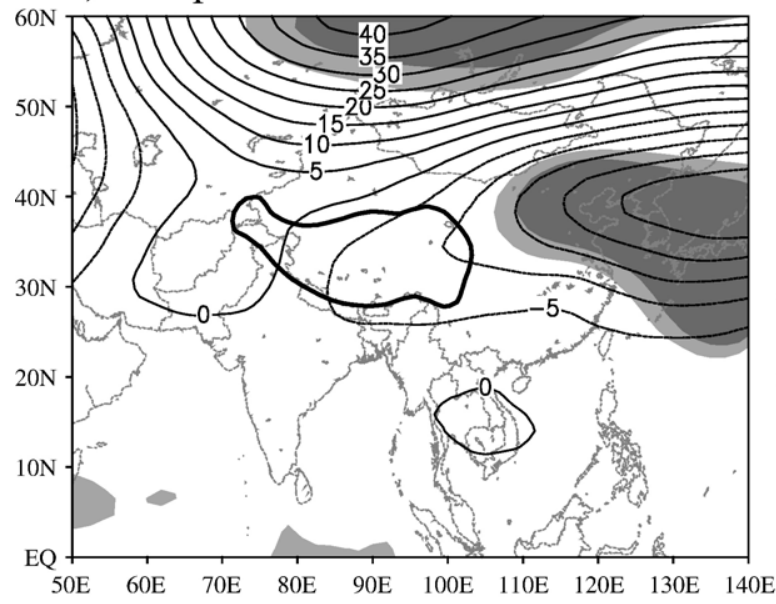

c) $500 \mathrm{hpa} \mathrm{DJF}$

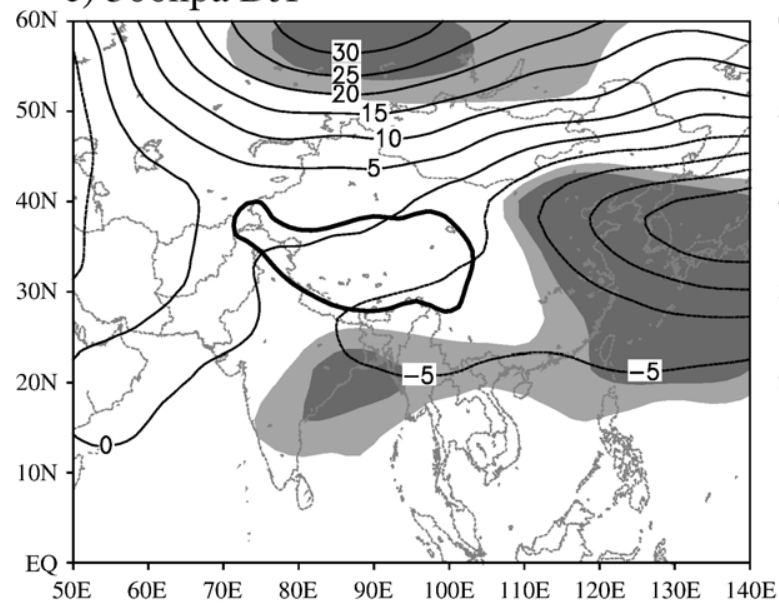

e) $850 \mathrm{hpa} \mathrm{DJF}$

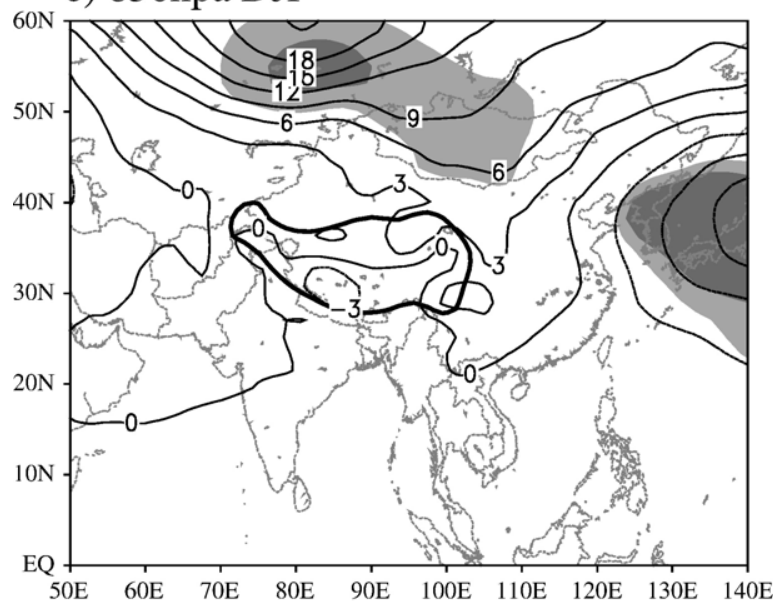

b) $200 \mathrm{hpa} \mathrm{JJA}$

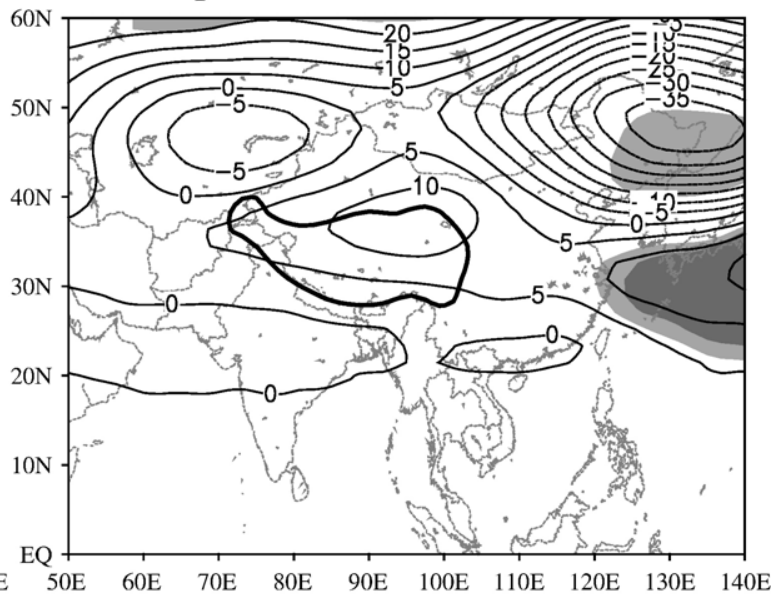

d) $500 \mathrm{hpa} \mathrm{JJA}$

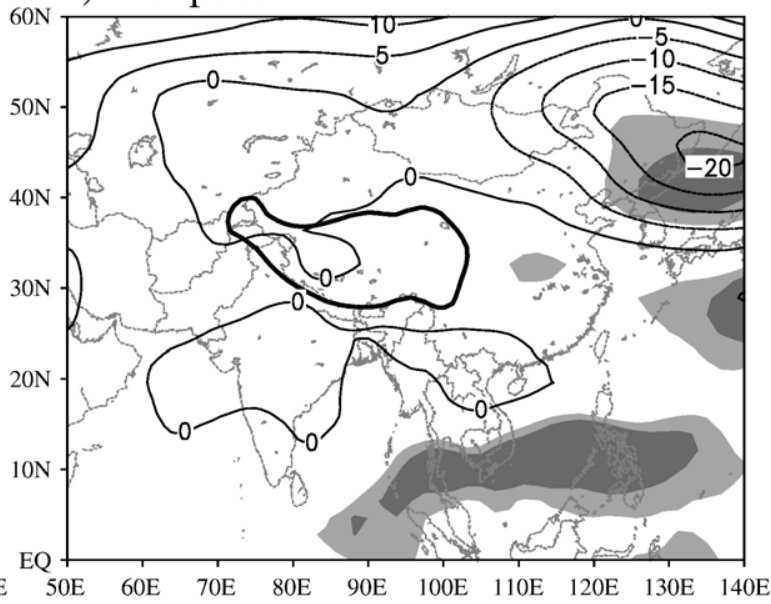

f) $850 \mathrm{hpa} \mathrm{JJA}$

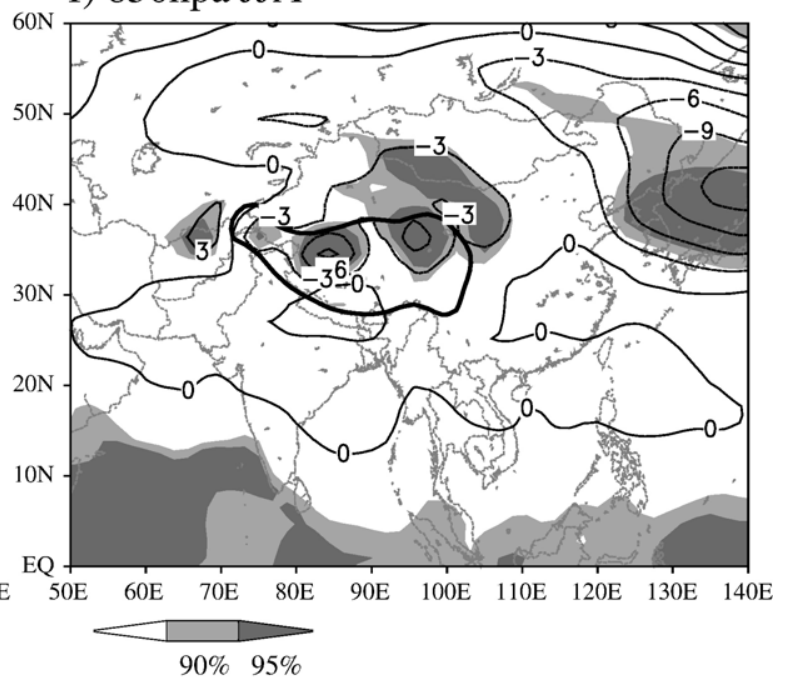

Fig. 13. The difference (current minus natural) of geopotential heights at 200, 500, and 850 hpa (from top to bottom) in DJF (left) and JJA (right), respectively. The thick black contour line shows the Tibetan Plateau. The values of geopotential height at 850 hpa on the Tibetan Plateau are only for reference, since the mean pressure on it is higher than $600 \mathrm{hpa}$. 
remote impact of LUC on the TP, the analysis in the following section focuses on the Asian monsoon region.

Fig. 13 shows the changes (current minus natural scenario) of geopotential height in winter (DJF) and summer (JJA) at $200 \mathrm{hpa}, 500 \mathrm{hpa}$ and $850 \mathrm{hpa}$, respectively. Significant levels at $90 \%$ and $95 \%$ are shaded. In winter, the geopotential heights are increased on the north of the TP at all levels, which will weaken the westerlies in this region, while the geopotential heights decrease to the east of the TP. The trough centered at $140^{\circ} \mathrm{E}, 50^{\circ} \mathrm{N}$ is strengthened and deeper, intensifying the winter monsoon in East Asia. In summer, the anticyclone over the TP at 200 hpa gets stronger, however it does not pass the $90 \%$ significance level. The geopotential height gets lower in lower troposphere, which will intensify the

a) MAM

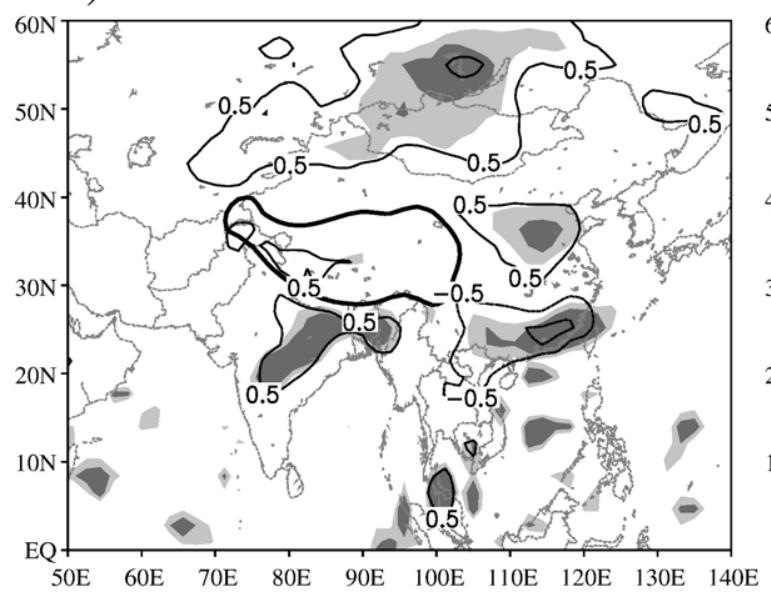

c) $\mathrm{SON}$

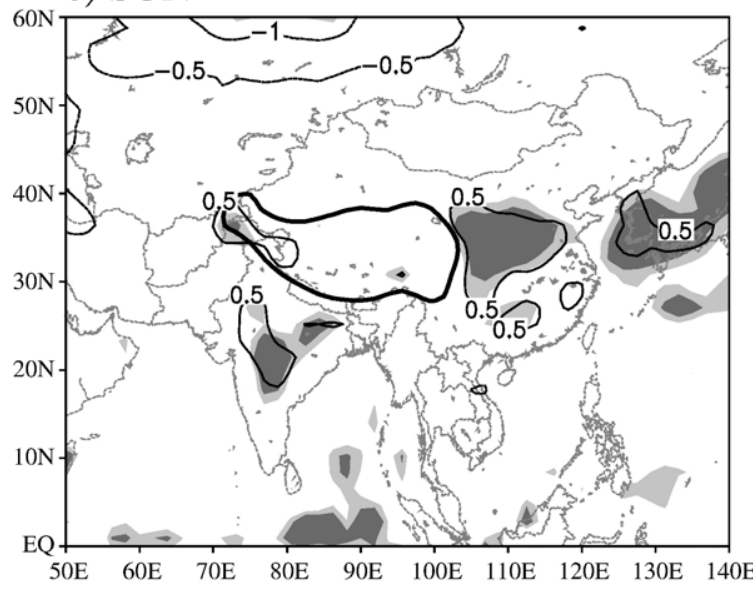

special pressure system over the TP and thus strengthen summer monsoon on the TP. There is a weakening center of pressure to the northeast of Asia at all levels in summer, strengthening the Northwest Pacific anticyclone. However, this decreasing center also prevents the wind blowing further from the Pacific to north China, suggesting that the East Asia summer monsoon in North China is weakened. The circulation changes provide the dynamical basis for the impact of LUC transmitting to remote regions.

Fig. 14 presents the temperature changes (current minus natural scenario) for the Asian region. In spring temperature increases in North China and Mongolia and also in the south of the Himalayas and India. Temperature also increases at the western TP, however, it does not pass the $90 \%$ significance level. In southern China, the temperature decreases along the costal regions.

b) JJA

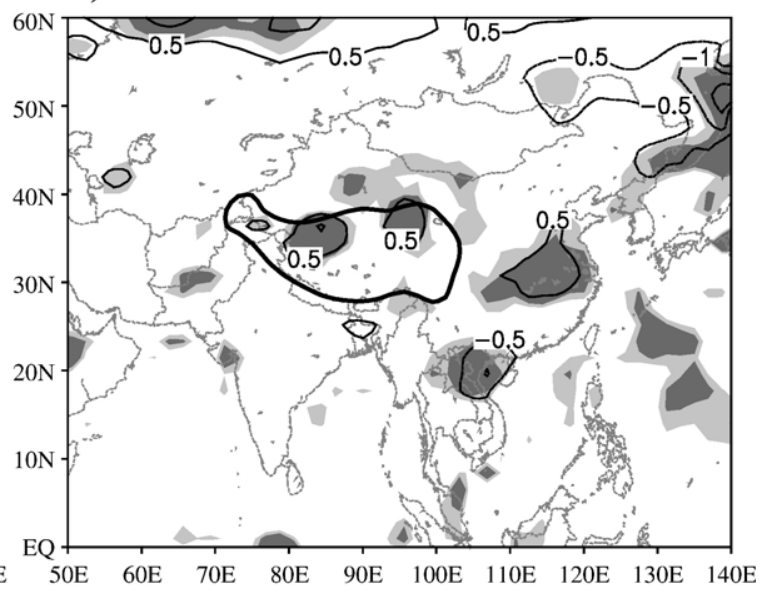

d) $\mathrm{DJF}$

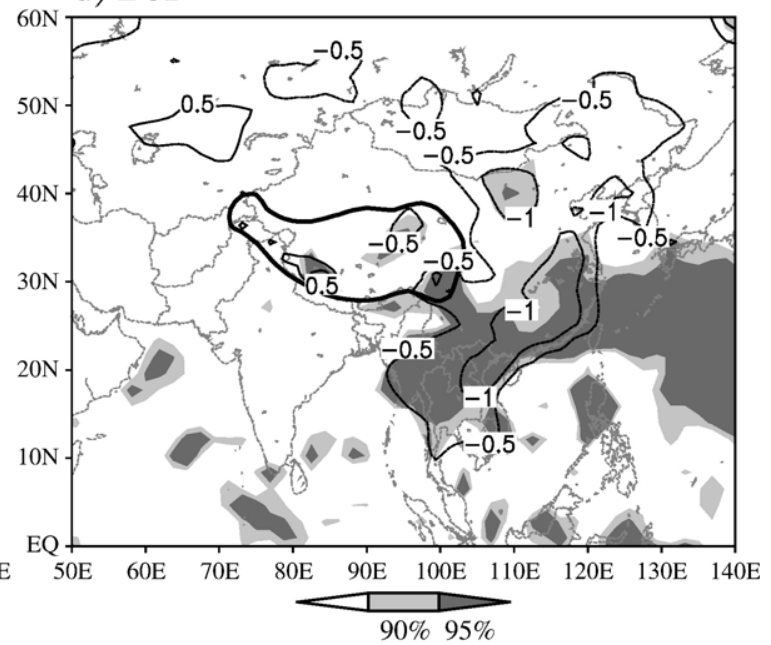

Fig. 14. The difference (current minus natural) of daily 2-m temperature in four seasons. The thick black contour line shows the Tibetan Plateau. 
The warming trends at northern China, India, and western TP last till summer and autumn. In winter, the temperature decreases in entire East Asia, centered at south-central China.

In tropical deforestation studies, it was found that the conversion of tropical forests into croplands significantly affected mean precipitation and evaporation due to local changes in tropical convection (e.g. Shukla et al., 1990). In mid-latitude deforestation studies, little change in the global scale hydrological cycle is found due to land use change (e.g. Govindasamy et al., 2001), suggesting that the precipitation dynamics in the midlatitudes are less affected by local convection but dominated by large-scale condensation associated with baroclinically driven storm tracks. The effect of LUC on the TP on rainfall over the Asian region is shown in

\section{a) MAM}

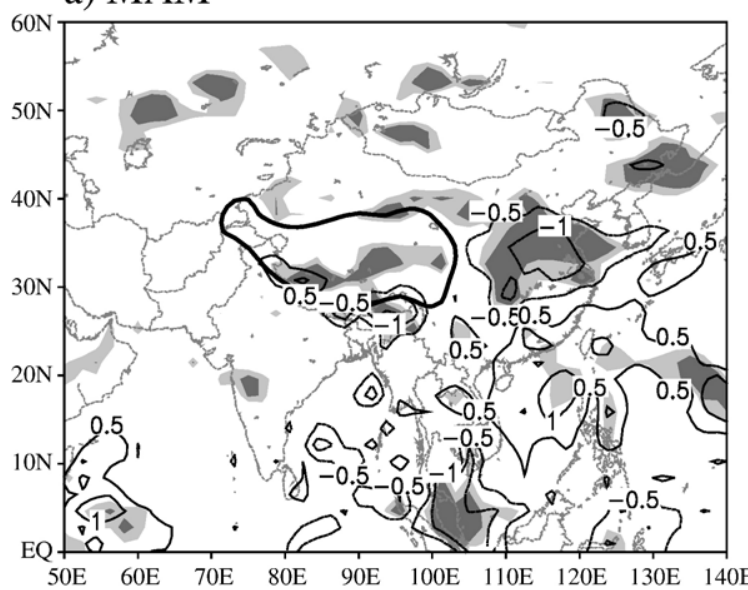

c) $\mathrm{SON}$

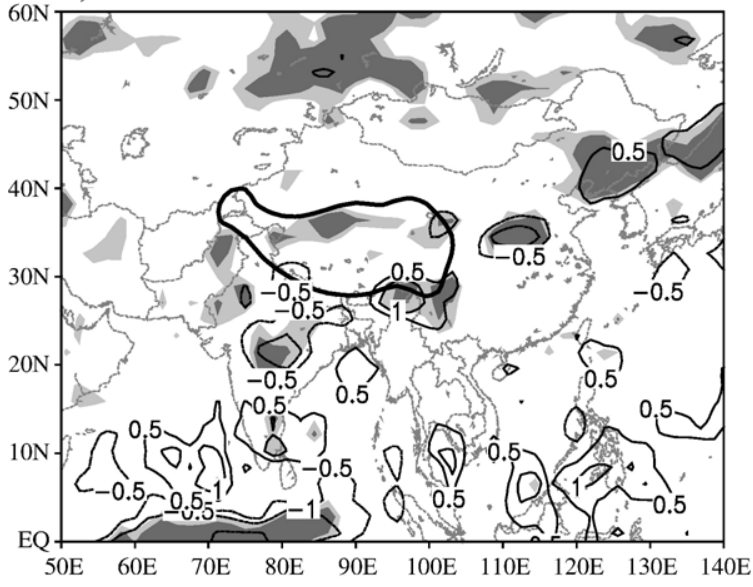

Fig. 15. In spring, rainfall in the western Himalayas is intensified, which agrees well with the measurements from tree ring discussed in Section 1. The rainfall is intensified in the South China Sea region and lasts almost all year round, although it is not always statistically significant. In central China, north of the Yangtze River valley, rainfall is weakened dramatically and this decrease lasts until summer with the center shifted southerly. In summer, the rainfall in India is intensified, but it is not statistically significant and it changes its sign in autumn. Considering the TP is the source for several major rivers in Asia, including Huanghe River, Yangtze River, Mekong River, and Salween River, the remote effects found in this study suggest that the land use changes on the TP should be considered when assessing flood/drought studies in India and China. Discussions in b) JJA

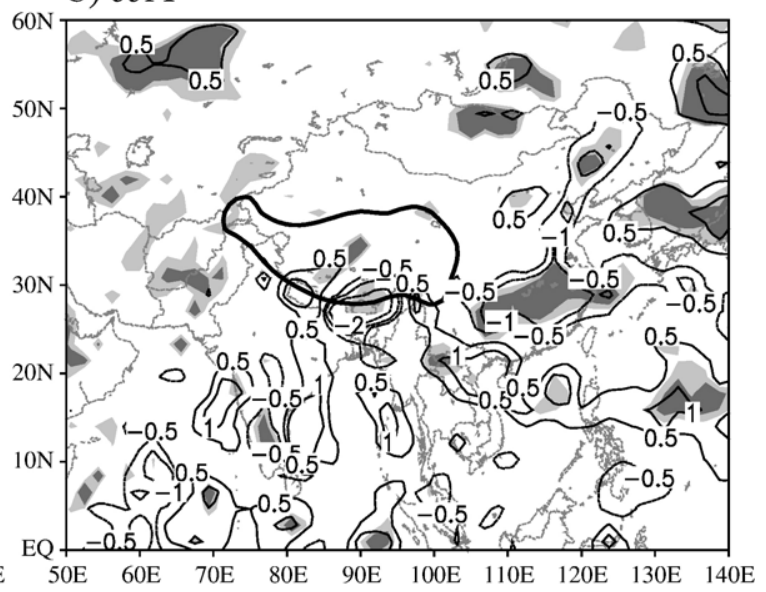

d) DJF

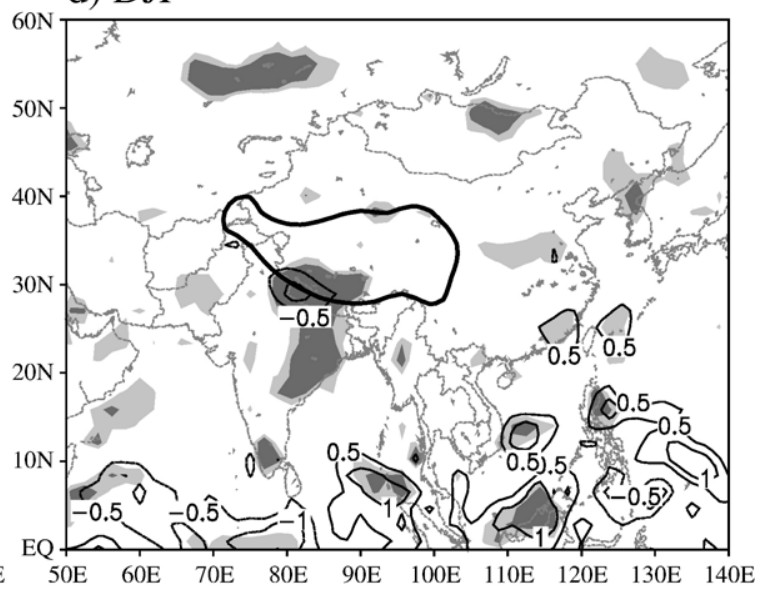

$90 \% 95 \%$

Fig. 15. Same as Fig. 14, but for monthly mean precipitation. 
Section 3.1 show that there are high uncertainties in the evaluation of the mean precipitation on the TP not only in the global observation datasets or in our model simulation. More accurate simulation of the regional climate, especially the precipitation, on the Tibetan Plateau should be addressed in the future.

A summary of the annual mean difference between natural and current scenarios for the area averaged values over the TP region is given in Table 3. The current area average LAI and fractional vegetation are lower than is the potential vegetation cover, leading to a decreasing surface albedo. The land surface changes lead to higher pressure and temperature at $200 \mathrm{hpa}$ and $500 \mathrm{hpa}$ levels. The large-scale circulation changes will result in surface temperature and surface evaporation increasing and rainfall decreasing. It can be concluded that the TP is warmer $\left(0.17^{\circ}\right)$ and drier $(-0.03 \mathrm{~mm} /$ day $)$ under current than non-anthropogenically influenced land cover.

Fig. 16 shows the global response of geopotential heights at 200 hpa and 500 hpa to the land cover change on TP, respectively. The circulation changes mainly in the middle and high latitude regions. There are several enhanced centers, e.g. Siberia, southwest America, south Indian Ocean, and southeast Australia, and south Brazil mainly at $200 \mathrm{hpa}$ level and several weakening centers as well, e.g. Canada, Drake Passage between South America and Antarctica, and a small region located in the

\section{a) $200 \mathrm{hpa}$}

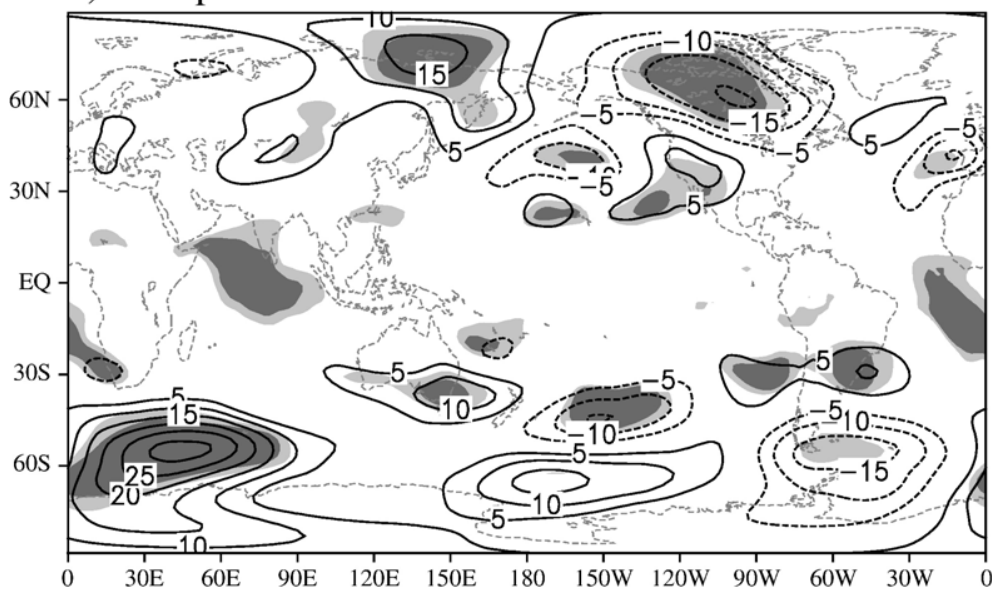

b) $500 \mathrm{hpa}$

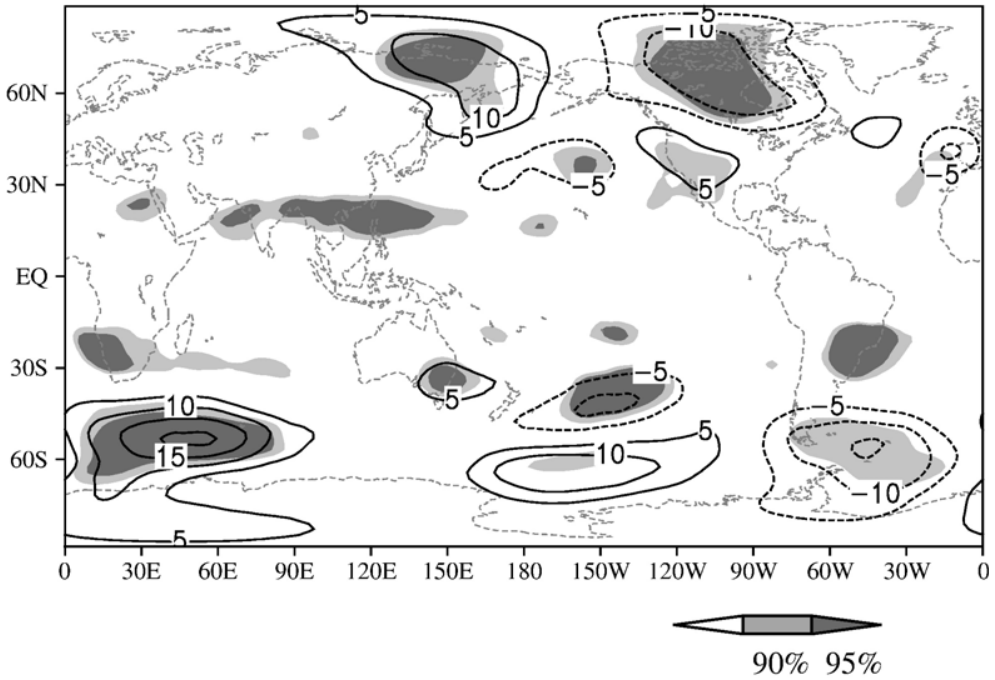

Fig. 16. Globally difference (current minus natural, contour line) of annual mean geopotential heights at a) 200 hpa and b) 500 hpa, respectively. Significant levels are shaded at $90 \%$ and $95 \%$ levels, respectively. 
North Pacific Ocean centered at $35^{\circ} \mathrm{N}, 160^{\circ} \mathrm{W}$ area. All these changes of circulation will reflect the changing patterns of temperature, as seen later. The mechanisms of such changes of circulation are complicated and cannot be well explained by only one scenario run in the present paper. More studies concerning this point should be performed in future.

Fig. 17 shows the global change of the 10 -year mean daily temperature and yearly precipitation due to LUC on the TP. Statistical significances are also provided at $90 \%$ and $95 \%$. The distributions of temperature changes are highly related to the changes of circulation shown in Fig. 16. Several regions including Siberia, USA, and South America are warmer, while Europe, Canada and Africa are colder as a result of humaninduced LUC on the TP. Asia, northwest China, Mongolia and India are getting warmer while northeast China, Southeast Asia are getting colder with current land cover on TP. However, not all changing centers pass the significant levels. Siberia, North America, Brazil, Southeast Asia are statistically significant. It is interesting to find the changes at the Polar Regions are also statistically significant. As discussed in Section 2.2 , the statistical significance still needs to be ascertained by further physical insight. Fig. 17c shows that rainfall is intensified over Southeast Asia, Sea of Japan, west Pacific centered at $20^{\circ} \mathrm{N}, 180^{\circ}$ area, the Gulf of Mexico, and southwest of the Indian Ocean. Decreases of rainfall can also be found in several regions including central China, northeast of the Indian Ocean, the western Pacific along the Equator and Brazil. As shown in Fig. 17d, only small proportions of these changes are statistically significant. Since precipitation is highly related to the local or regional processes, remote impacts should be treated cautiously. We suggest more scenario experiments including land surface boundary a) Annual mean $2 \mathrm{~m}$ Temperature

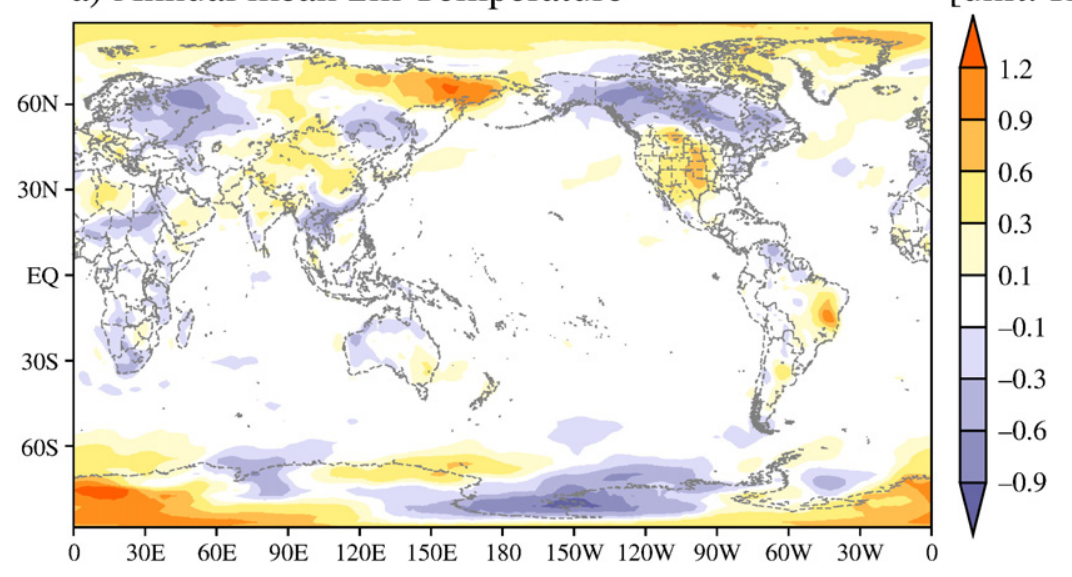

b) Significant level

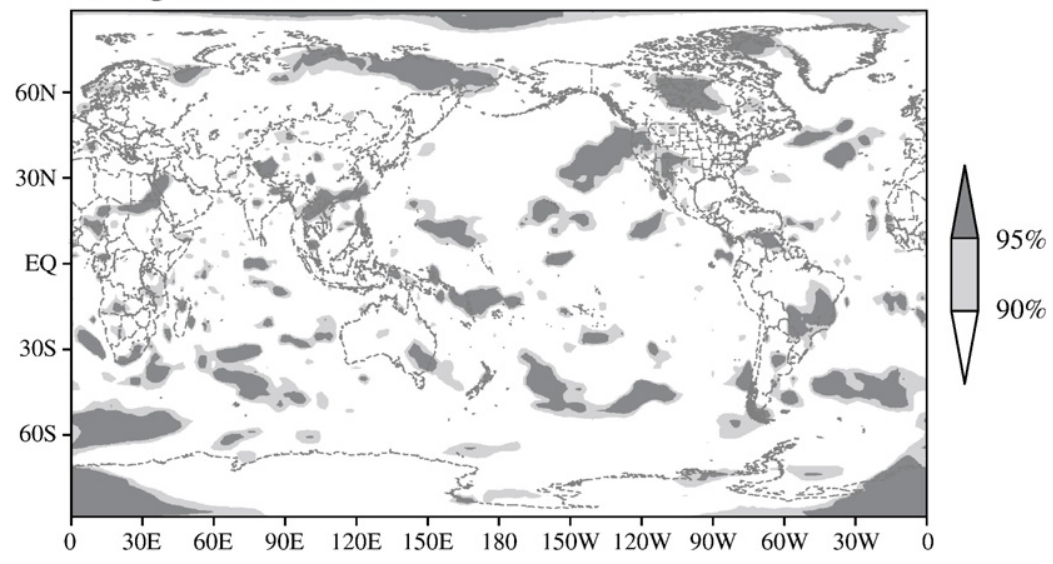

Fig. 17. Globally difference (current minus natural) of a) daily 2-m temperature and c) yearly mean precipitation and corresponding significant levels at b) and d) at $90 \%$ and $95 \%$ levels, respectively. 
c) Yearly mean precipitation

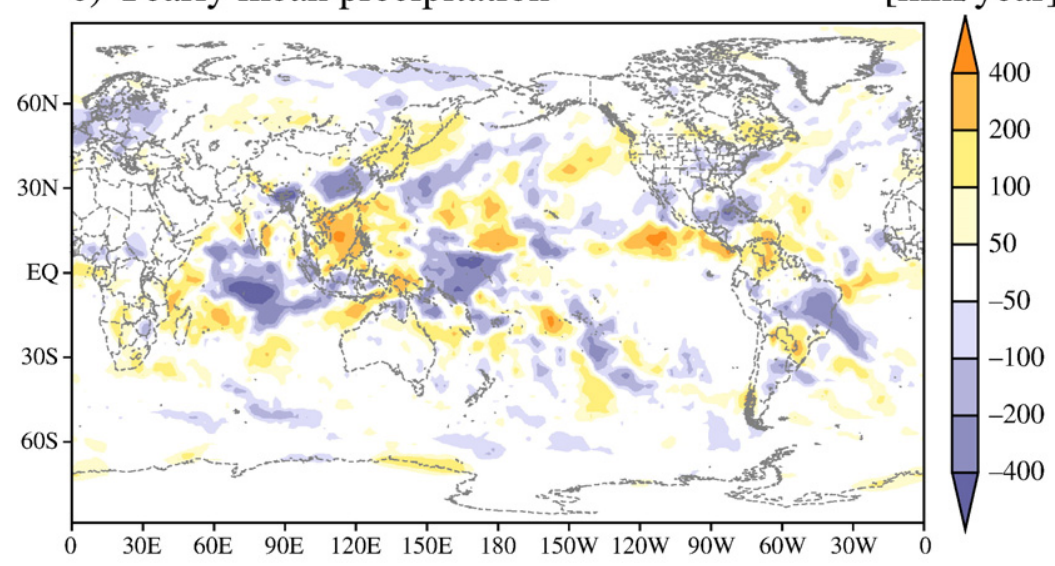

d) Significant level

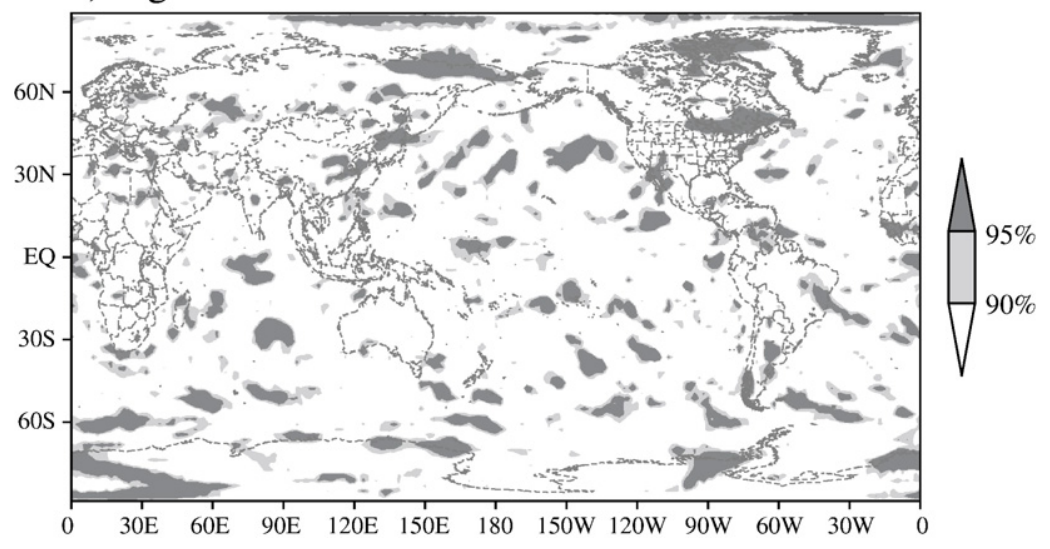

Fig. 17 (continued). changes to be performed for the TP in future. There is strong warming, but only relatively small changes of precipitation in the Polar Regions. This response of the polar climate to LUC on the TP may shed some light on the poor ability of most GCMs to accurately represent Arctic Climate due to parameterization and numerical methods (Randall et al., 1998). The area averages for the

Table 4

Comparison of 10 years daily mean temperature and yearly mean precipitation from current and natural simulation for Northern Hemisphere $\left(\mathrm{NH}\right.$; Equator- $\left.70^{\circ} \mathrm{N}\right)$, Southern Hemisphere $\left(\mathrm{SH} ; 70^{\circ} \mathrm{S}-\right.$ Equator), and the whole globe $\left(70^{\circ} \mathrm{S}-70^{\circ} \mathrm{N}\right)$

\begin{tabular}{|c|c|c|c|c|c|c|}
\hline \multirow[t]{2}{*}{ Regions } & \multicolumn{3}{|c|}{$\begin{array}{l}\text { Temperature } \\
{[\mathrm{K}]}\end{array}$} & \multicolumn{3}{|c|}{$\begin{array}{l}\text { Precipitation } \\
\text { [mm/year] }\end{array}$} \\
\hline & Current & Natural & $\begin{array}{l}\text { Current } \\
\text { minus } \\
\text { Natural }\end{array}$ & Current & Natural & $\begin{array}{l}\text { Current } \\
\text { minus } \\
\text { Natural }\end{array}$ \\
\hline $\mathrm{NH}$ & 290.113 & 290.104 & 0.009 & 1135.70 & 1128.12 & 7.58 \\
\hline $\mathrm{SH}$ & 289.587 & 289.585 & 0.002 & 1089.27 & 1094.72 & -5.45 \\
\hline Globe & 289.850 & 289.845 & 0.005 & 1112.49 & 1111.42 & 1.07 \\
\hline
\end{tabular}

North Hemisphere $\left(0^{\circ}-70^{\circ} \mathrm{N}\right)$, South Hemisphere $\left(0^{\circ}-\right.$ $\left.70^{\circ} \mathrm{S}\right)$ and the globe $\left(70^{\circ} \mathrm{S}-70^{\circ} \mathrm{N}\right)$ are listed in Table 4.

\section{Conclusion and discussions}

We have performed "equilibrium" climate simulations using the most recent version of the Max Planck Institute for Meteorology atmospheric general circulation model, ECHAM5. Our analysis shows that anthropogenic land use changes (LUC) on the Tibetan Plateau (TP) influence the local and remote climate. Specifically, the TP is warmer $\left(0.17^{\circ} \mathrm{C}\right)$ and drier $(-9 \mathrm{~mm} / \mathrm{year})$ than it would be without anthropogenic LUC. The TP has been observed to warm over recent decades, corresponding with a concurrent human-induced LUC towards urban and desertified areas. This trend towards warming is shown in our model experiments. We hypothesize that at least some of the observed TP temperature increase is due to the human-induced LUC. More observational studies of the characteristics of precipitation 
changes on the TP will help to validate or refute this hypothesis. Human-induced LUC on the TP results in an intensification of the Indian summer monsoon and a weakening of the East Asia monsoon in China. The latter helps to explain the weakening of the East Asia monsoon in last 120 years $(\mathrm{Fu}, 2003)$. The global climate due to LUC on the TP is slightly wetter $(+1 \mathrm{~mm}$ per year), but no distinct temperature changes in the model simulations are observed.

It should be kept in mind that the results mentioned above are obtained from the response of only one simulation to local LUC on the TP and, therefore, should be treated qualitatively but not quantitatively. One potential source of uncertainty that we have not completely accounted for is our ability to simulate the local climate system on the TP. The detailed local response is uncertain because we have not precisely resolved either the terrain or individual storms. However, the large-scale patterns match well with observations. It is possible that other GCMs would yield quantitatively different results, because the results may be highly sensitive to the formulation of the model and the parameterization of various physical processes. As an example, the evaluation of impacts of deforestation in the Amazonian River basin from different studies diverges considerably in magnitude and even sign of the impacts (Lean and Rowntree, 1997). Experience with global (AMIP; Gates et al., 1999) and regional (Project to Intercompare Regional Climate Simulations (PIRCS); Gutowski et al., 1998) climate modeling has demonstrated the usefulness of intercomparing model results. It is suggested therefore that more studies evaluating impacts of land use changes on the Tibetan Plateau would supplement the results reported here.

The goal of this study was to highlight the response of the climate system to changes in land cover. SST and sea ice are prescribed to isolate the influence of the land use change. In the future, it will be valuable to perform simulations with an interacting ocean, allowing for the effects of El Niño-Southern Oscillation. Grassland currently occupies about $50 \%$ of the TP and may act as a carbon sink nowadays ( $\mathrm{Du}$ et al., 2004). It will be interesting to perform future scenario experiments that include effects of greenhouse gas, like $\mathrm{CO}_{2}$, when assessing the impact of the future land cover change on the TP.

Additionally, an improved parameterization of convection suitable for steep landscape heterogeneity and a higher resolution could increase the reliability of the model simulations. Regional or meso-scale models embedded within GCMs may be able to assess more realistically the consequences of LUC on local scales, especially when those occur with high spatial heterogeneity. Cui et al. (2004) concluded that a regional model might improve the local climate simulation on the TP than GCMs. Such nested model system may help not only to specify the local response to LUC but also transfer or downscale the information from global models. Generally very high resolution or locally adjusted grids will be necessary to fully account for the effects of TP ecological modifications on large scale and global climate.

\section{Acknowledgements}

We thank two anonymous reviewers and Jimmy Adegoke, in particular, for making many useful comments and suggestions for improvements in this manuscript. We also thank Stefan Hagemann, Anglika Heil and Melissa Pfeffer at MPI for their suggestions on the manuscript and Irene Fischer-Bruns for help on statistics. This study is supported by the ENTEAM project under the Chinese Academy Science and Max Planck Society (CAS-MPG) cooperation framework. The simulations have been carried out at the German Climate Computing Center (DKRZ).

\section{References}

Adler, R.F., Susskind, J., Bolvin, D., Nelkin, E., Chang, G.J., Ferraro, A., Gruber, A.R., Xie, P., Janowiak, J., Rudolf, B., Schneider, U., Curtis, S., Arkin, P., 2003. The version 2 Global Precipitation Climatology Project (GPCP) monthly precipitation analysis (1979-present). J. Hydrometeorol. 4 (6), 1147-1167.

Bengtsson, L., Arpe, K., Roeckner, E., Schulzweida, U., 1996. Climate predictability experiments with a general circulation model. Clim. Dyn. 12, 261-278.

Beniston, M., 2003. Climatic change in mountain regions: a review of possible impacts. Clim. Change 59, 5-31.

Bonan, G.B., 1997. Effects of land use on the climate of the United States. Clim. Change 37, 449-486.

Braeuning, A., Mantwill, B., 2004. Summer temperature and summer monsoon history on the Tibetan Plateau during the last 400 years recorded by tree rings. Geophys. Res. Lett. 31, L24205. doi:10.1029/ 2004GL020793.

Broccoli, A.J., Manabe, S., 1992. The effect of orography on middle latitude northern hemisphere dry climates. J. Climate 5, 1181-1201.

Charney, J.G., 1975. Dynamics of deserts and droughts in the Sahel. Q. J. R. Meteorol. Soc. 101, 193-202.

Clark, D., Xue, Y., Valdes, P., Harding, R., 2001. Impact of land surface degradation over different subregions in Sahel on climate in tropical North Africa. J. Climate 14, 1809-1822.

Cole, J.E., Rubd, D., Faurbanks, R.G., 1994. Isotopic response to international climate variability simulated by an atmospheric general circulation model. Quat. Sci. Rev. 12, 387-406.

Cui, X.F., Graf, H.F., Langmann, B., Chen, W., Huang, R.H., 2004. Evaluation of daily precipitation in 1998 summer over the Tibetan Plateau using REMO. Proceedings of the 4th International Symposium on the Tibetan Plateau, Aug. 4-7, Lhasa, China, p. 146.

Du, M., Kawashima, S., Yonemura, S., Zhang, X., Chen, S., 2004. Mutual influence between human activities and climate change in the Tibetan Plateau during recent years. Glob. Planet. Change 41, 241-249. 
Duemenil Gates, L.D., Liess, S., 2001. Impacts of deforestation and afforestation in the Mediterranean region as simulated by the MPI atmospheric GCM. Glob. Planet. Change 30, 309-328.

Frauenfeld, O.W., Zhang, T., Serreze, M.C., 2005. Climate change and variability using European Centre for Medium-Range Weather Forecasts reanalysis (ERA40) temperatures on the Tibetan Plateau. J. Geophys. Res. 110, D02101. doi:10.1029/2004JD005230.

Fu, C.B., 2003. Potential impacts of human-induced land cover change on East Asia monsoon. Glob. Planet. Change 37, 219-229.

Gates, W.L., Boyle, J.S., Covey, C., Dease, C.G., Doutriaux, C.M., Drach, R.S., Fiorino, M., Gleckler, P.J., Hnilo, J.J., Marlais, S.M., Philips, T.J., Potter, G.L., Santer, B.D., Sperber, K.R., Taylor, K.E., Williams, D.N., 1999. An overview of the results of the Atmospheric Model Intercomparison Project (AMIP). Bull. Am. Meteorol. Soc. 80, 29-55.

Govindasamy, B., Duffy, P.B., Caldeira, K., 2001. Land use changes and Northern Hemisphere cooling. Geophys. Res. Lett. 28 (2), 291-294.

Gutowski, W.J., Takle, E.S., Arritt, R.W., 1998. Project to intercompare regional climate simulations, Workshop II, 5-6 June, 1997. Bull. Am. Meteorol. Soc. 79, 657-659.

Hagemann, S., 2002. An improved land surface dataset for global and regional climate models. Report No. 336, Max-Planck-Institut fuer Meteorologie, Hamburg, p. 10.

Henderson-Sellers, A., Dickinson, R.E., Durbidge, T.B., Kennedy, P.J., McGuffie, K., Pitman, A.J., 1993. Tropical deforestation modeling local-scale and regional-scale climate change. J. Geophys. Res. 98, 7289-7315.

Kalnay, E., Cai, M., 2003. Impact of urbanization and land-use change on climate. Nature 423 (6939), 528-531.

Kanamitsu, M., Ebisuzaki, W., Woolen, J., Potter, J., Fiorino, M., 2002. NCEP/DOE AMIP-II reanalysis (R-2). Bull. Am. Meteorol. Soc. 83, 1631-1643.

Kang, I.S., Jin, K., Wang, B., Lau, K.M., Shukla, J., Krishnamurthy, V., Schubert, S.D., Wailser, D.E., Stern, W.F., Kitoh, A., Meehl, G.A., Kanamitsu, M., Galin, V.Y., Satyan, V., Park, C.K., Liu, Y., 2002. Intercomparison of the climatological variations of Asian summer monsoon precipitation simulated by 10 GCMs. Clim. Dyn. 19, 383-395.

Kistler, R., Kalnay, E., Collins, W., Saha, S., White, G., Woollen, J., Chelliah, M., Ebisuzaki, W., Kanamitsu, M., Kousky, V., van den Dool, H., Jenne, R., Fiorino, M., 2001. The NCEP-NCAR 50-year reanalysis: monthly means CD-ROM and documentation. Bull. Am. Meteorol. Soc. 82, 247-267.

Lean, J., Rowntree, P.R., 1997. Understanding the sensitivity of a GCM simulation of Amazonian deforestation to the specification of vegetation and soil characteristics. J. Climate 10 (6), 1216-1235.

Li, X., Cheng, G.D., 1999. A GIS aided response model of high altitude permafrost to global change. Sci. China, Ser. D 42 (1), 72-79.

Liu, X.D., Chen, B., 2000. Climate warming in the Tibetan Plateau during recent decades. Int. J. Climatol. 20, 1729-1742.

Liu, X., Yin, Z.Y., 2002. Sensitivity of East Asian monsoon climate to the Tibetan Plateau uplift. Palaeogeogr. Palaeoecol. 183, 223-245.

Lott, F., 1999. Alleviation of stationary biases in a GCM through a mountain drag parameterization scheme and a simple representation of mountain lift forces. Mon. Weather Rev. 127, 788-801.

Lott, F., Miller, M., 1997. A new subgrid scale orographic drag parameterization: its testing in the ECMWF model. Q. J. R. Meteorol. Soc. 123, 101-127.

Loveland, T.R., Reed, B.C., Brown, J.F., Ohlen, D.O., Zhu, J., Yang, L., Lott, F., 1999. Alleviation of stationary biases in a GCM through a mountain drag parameterization scheme and a simple representation of mountain lift forces. Mon. Weather Rev. 127, 788-801.
Manabe, S., Terpsta, T.B., 1974. The effects of mountains on the general circulation of the atmosphere as identified by numerical experiments. J. Meteorol. Soc. Jpn. 31, 3-42.

Murakami, T., 1958. The sudden change of upper westerlies near the Tibetan Plateau at the beginning of summer season. J. Meteorol. Soc. Jpn. 36, 239-247.

New, M., Lister, D., Humle, M., Makin, I., 2002. A high-resolution data set of surface climate over global land areas. Clim. Res. 21, 1-25.

Niu, T., Chen, L., Zhou, Z., 2004. The characteristics of climate change over the Tibetan Plateau in the last 40 years and the detection of the climate jumps. Adv. Atmos. Sci. 21 (2), 193-203.

Nobre, C.A., Sellers, P.J., Shukla, J., 1991. Amazonian deforestation and regional climate change. J. Climate 4, 975-988.

Ojima, D., et al., 2000. Land Use/Land Cover Change in Temperate East Asia: Current Status and Future Trend. International START secretariat, Washington DC, USA, p. 228.

Pan, Z., Eugene, T., Segal, M., Arritt, R., 1999. Simulation of potential impacts of man-made land use changes on U.S. summer climate under various synoptic regimes. J. Geophys. Res. 104, 6515-6528.

Qin, B., Huang, Q., 1998. Evaluation of the climatic change impacts on the inland lake - a case study of Lake Qinghai, China. Clim. Change 39 (4), 695-714.

Rajendran, K., Kitoh, A., Yukimoto, S., 2004. South and East Asian summer monsoon climate and variation in MRI coupled model (MRI-CGCM2). J. Climate 17, 763-782.

Ramankutty, N., Foley, J.A., 1999. Estimating historical changes in global and cover: croplands from 1700 to 1992. Glob. Biogeochem. Cycles 13 (4), 997-1027.

Randall, D., Curry, J., Battisti, D., Flato, G., Grumbine, R., Hakkinen, S., Martinson, D., Preller, R., Walsh, J., Weatherly, J., 1998. Status of and outlook for large-scale modeling of atmosphere-ice-ocean interactions in the Arctic. Bull. Am. Meteorol. Soc. 79 (2), 197-219.

Roeckner, E., Bauml, G., Bonaventura, L., Brokopf, R., Esch, M., Giorgetta, M., Hagemann, S., Kirchner, I., Kornblueh, L., Manzini, E., Rhodin, A., Schlese, U., Schulzweida, U., Tompkins, A., 2003. The atmospheric general circulation model ECHAM5. Part I: model description. Report No. 349, Max-Planck-Institut fuer Meteorologie, Hamburg, pp. 5-6.

Roeckner, E., Brokopf, R., Esch, M., Giorgetta, M., Hagemann, S., Kornblueh, L., Manzini, E., Schlese, U., Schulzweida, U., 2004. The atmospheric general circulation model ECHAM5. Part II: sensitivity of simulated climate to horizontal and vertical resolution. Report No. 354, Max-Planck-Institut fuer Meteorologie, Hamburg, pp. 18-20.

Shukla, J., Nobre, C., Sellers, P.J., 1990. Amazon deforestation and climate change. Science 247, 1322-1325.

Simmons, A.J., Gibson, J.K., 2000. The ERA40 project plan. ERA40 Project Report Series No. 1. ECMWF, Reading, UK, p. 63.

Singh, J., Yadav, R.R., 2005. Spring precipitation variations over the western Himalaya, India, since A.D. 1731 as deduced from tree rings. J. Geophys. Res. 110, D01110. doi:10.1029/2004JD004855.

Snyder, P.K., Foley, J.A., 2004. Analyzing the effects of complete tropical forest removal on the regional climate using a detailed threedimensional energy budget: an application to Africa. J. Geophys. Res. 109, D21102. doi:10.1029/2003JD004462.

Suh, M.S., Lee, D.K., 2004. Impacts of land use/cover changes on surface climate over east Asia for extreme climate cases using RegCM2. J. Geophys. Res. 109, D02108. doi:10.1029/2003JD003681.

U.S. Geological Survey, 2001. Global land cover characteristics data base version 2.0. http://edcdaac.usgs.gov/glcc/globdoc2_0.html.

Vitousek, P.M., Mooney, H.A., Lubchenco, J., Melillo, J.M., 1997. Human domination of Earth's ecosystems. Science 277, 494-499. 
van den Hurk, B.J.J.M., Viterbo, P., Los, S.O., 2003. Impact of leaf area index seasonality on the annual land surface evaporation in a global circulation model. J. Geophys. Res. 108 (D6), 4191. doi:10.1029/ 2002JD002846.

von Storch, H., Zwiers, F.W., 1999. Statistical Analysis in Climate Research. Cambridge University Press, p. 113.

Wang, S.L., Jin, H.J., Li, S.X., Zhao, L., 2000. Permafrost degradation on the Qinghai-Tibet Plateau and its environmental impacts. Permafr. Periglac. Process. 11, 43-53.

Webster, P.J., Magaña, V.O., Palmer, T.N., Shukla, J., Tomas, R.A., Yanai, M., Yasunari, T., 1998. Monsoons: processes, predictability, and the prospects for prediction. J. Geophys. Res. 103 (C7), 14451-14510.

Werth, D., Avissar, R., 2002. The local and global effects of Amazon deforestation. J. Geophys. Res. 107 (D20), 8087. doi:10.1029/ 2001JD000717.

Xie, P., Arkin, P.A., 1997. Global precipitation: a 17-year monthly analysis based on gauge observation, satellite estimates and numerical model outputs. Bull. Am. Meteorol. Soc. 78, 2539-2558.
Xue, Y., 1996. The impact of desertification in the Mongolian and the Inner Mongolian grassland on the regional climate. J. Climate 9, 2173-2189.

Xue, Y., 1997. Biosphere feedback on regional climate in tropical North Africa. Q. J. R. Meteorol. Soc. 123 (B), 1483-1515.

Xue, Y., Juang, H.H., Li, W.P., Prince, S., DeFries, R., Jiao, Y., Vasic, R., 2004. Role of land surface processes in monsoon development: East Asia and West Africa. J. Geophys. Res. 109, D03105. doi:10.1029/2003JD003556.

Yatagai, A., Yasunari, T., 1995. Interannual variations of summer precipitation in the arid/semi-arid region in China and Mongolia. J. Meteorol. Soc. Jpn. 73, 909-923.

Ye, D., Gao, Y., 1979. The meteorology of the Qinghai-Xizang (Tibet) Plateau. Sciences Press, Beijing, p. 278 (in Chinese).

Zou, X., Li, S., Zhang, C., Dong, G., Dong, Y., Yan, P., 2002. Desertification and control plan in the Tibet Autonomous Region of China. J. Arid Environ. 51, 183-198. 